\title{
The immunoproteasome and viral infection: a complex regulator of inflammation
}

\author{
Mary K. McCarthy ${ }^{1}$ and Jason B. Weinberg ${ }^{1,2}$ * \\ ' Department of Microbiology and Immunology, University of Michigan, Ann Arbor, MI, USA \\ ${ }^{2}$ Department of Pediatrics and Communicable Diseases, University of Michigan, Ann Arbor, MI, USA
}

\section{Edited by:}

Hirofumi Akari, Kyoto University, Japan

\section{Reviewed by:}

Ikuo Shoji, Kobe University Graduate School of Medicine, Japan

Hiroyuki Yamamoto, AIDS Research

Center - National Institute of

Infectious Diseases, Japan

\section{${ }^{*}$ Correspondence:}

Jason B. Weinberg, Department of

Pediatrics and Communicable

Diseases, University of Michigan,

Ann Arbor, MI 48109, USA

e-mail: jbwein@umich.edu
During viral infection, proper regulation of immune responses is necessary to ensure successful viral clearance with minimal host tissue damage. Proteasomes play a crucial role in the generation of antigenic peptides for presentation on MHC class I molecules, and thus activation of CD8 T cells, as well as activation of the NF-kB pathway. A specialized type of proteasome called the immunoproteasome is constitutively expressed in hematopoietic cells and induced in non-immune cells during viral infection by interferon signaling. The immunoproteasome regulates CD8 T cell responses to many viral epitopes during infection. Accumulating evidence suggests that the immunoproteasome may also contribute to regulation of proinflammatory cytokine production, activation of the NF-kB pathway, and management of oxidative stress. Many viruses have mechanisms of interfering with immunoproteasome function, including prevention of transcriptional upregulation of immunoproteasome components as well as direct interaction of viral proteins with immunoproteasome subunits. A better understanding of the role of the immunoproteasome in different cell types, tissues, and hosts has the potential to improve vaccine design and facilitate the development of effective treatment strategies for viral infections.

Keywords: proteasome, immunoproteasome, viral pathogenesis, CD8 T cell, NF-kB

\section{INTRODUCTION}

The host outcome of viral infection depends on the successful balance of immune responses that contribute to control of viral replication, but those responses may also mediate aspects of host tissue damage that accompany infection. Antibodies, cytokines, CD4 T cells, and CD8 T cells can all play important roles in controlling viral replication and viral clearance from the host. CD8 $\mathrm{T}$ cells kill infected target cells by two major pathways: perforin/granzyme-mediated pathways and Fas-Fas ligand (FasL)-mediated pathways (Russell and Ley, 2002; Hoves etal., 2010). CD8 T cells can also contribute to elimination of infected cells through production of antiviral cytokines, such as IFN- $\gamma$ and TNF- $\alpha$. A number of viruses are eliminated at least partially through CD8 $\mathrm{T}$ cell-dependent mechanisms in mouse models, including lymphocytic choriomeningitis virus (LCMV), influenza virus, the mouse-specific orthopoxvirus ectromelia virus, and murine gammaherpesvirus (MHV-68; Ehtisham et al., 1993; Kägi et al., 1994; Walsh et al., 1994; Müllbacher et al., 1999). However, CD8 T cells can also contribute to CNS, liver, and cardiac pathology during infection with LCMV and coxsackievirus B3 (Buchmeier et al., 1980; Henke et al., 1995; Lang et al., 2008).

CD8 $\mathrm{T}$ cells recognize peptides bound to MHC class I molecules. The generation of peptide-MHC class I complexes involves many steps (Figure 1). Peptides that bind tightly to MHC class I are 8-11 amino acids in length and have anchor residues, which are generally in the $\mathrm{C}$-terminus, but can be present elsewhere in the peptide sequence (Falk etal., 1991). The vast majority of these peptides are generated by proteasomes (Rock et al., 1994), although extended versions of peptides produced by the proteasome can be trimmed by aminopeptidases in the cytosol (Stoltze et al., 2000) or endoplasmic reticulum (ER; Snyder et al., 1994; Craiu et al., 1997a). Peptides are transported from the cytoplasm to the ER by an ER-resident heterodimeric protein called transporter for antigen processing (TAP; Neefjes et al., 1993). TAP is a subunit of the MHC class-I-loading complex, a $\sim 1 \mathrm{MDa}$ complex within the ER, that clusters the molecules involved in MHC class I loading in order to increase the efficiency of the process. Once a peptide is successfully bound, the MHC class I molecule is released from the MHC class-I-loading complex and delivered to the cell surface for presentation to CD8 $\mathrm{T}$ cells.

Activation of CD8 T cells depends on the proteasome for generation of antigenic peptides presented on MHC class I molecules on the surface of either infected cells or antigen presenting cells (APCs). The immunoproteasome is a specialized type of proteasome with altered peptide cleavage properties that is constitutively expressed in hematopoietic cells and induced in non-immune cells under conditions of inflammation. Evidence suggests that the immunoproteasome may play an important role during viral infection through regulation of CD8 T cell responses and proinflammatory cytokine production, activation of the NF- $\mathrm{kB}$ pathway, and management of oxidative stress (Groettrup et al., 2009; Ebstein etal., 2012; Basler etal., 2013b; Warnatsch et al., 2013).

\section{STANDARD PROTEASOMES AND IMMUNOPROTEASOMES}

Proteasomes are large complexes responsible for the regulated degradation of almost all cellular proteins, and as such proteasome 


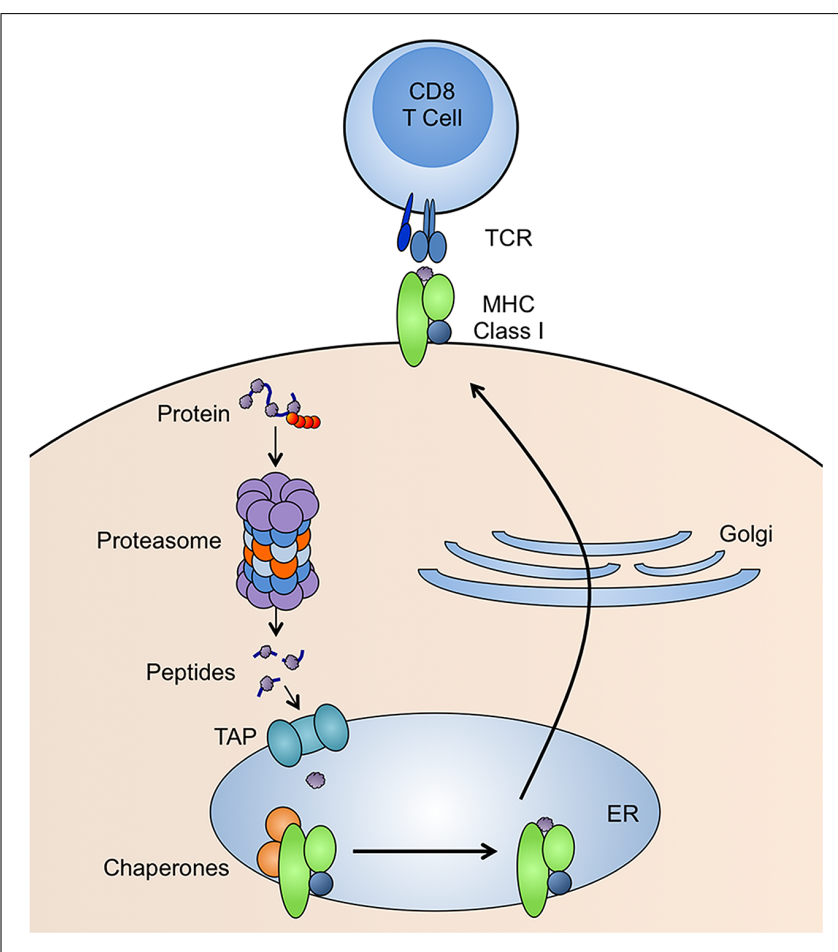

FIGURE 1 | MHC class I antigen presentation pathway. Proteins with ubiquitin tags (red spheres) are degraded by proteasomes and the resulting peptides are transported into the endoplasmic reticulum (ER) by TAP. In the $\mathrm{ER}$, the peptide is loaded onto MHC class I molecules by many molecular chaperones. The peptide-MHC class I complex is then transported to the cell surface for presentation to CD8T cells.

activity is required for cell viability (Rock et al., 1994; Tanaka, 1995). Proteasomes also play a primary role in the generation of antigenic peptides for presentation on MHC class I molecules, but not on MHC class II (Rock et al., 1994; Groettrup et al., 1996c; Craiu et al., 1997b). The 20S proteasome core is a barrel-shaped complex that is composed of four stacked heptameric rings: two outer alpha rings and two inner beta rings (Figure 2A; Groll et al., 1997; Unno etal., 2002). The proteasome may be associated with activator caps, discussed below. The catalytic activity is restricted to three of the beta subunits, $\beta 1$ (also called Y in vertebrates), $\beta 2(\mathrm{Z})$, and $\beta 5(\mathrm{X})$, that account for the caspase-like, trypsin-like, and chymotrypsin-like activities of the proteasome, respectively (DeMartino and Slaughter, 1999). The active sites of each of these proteins face toward the lumen of the proteasome cylinder, preventing unrestricted exposure of cytosolic proteins to proteolysis.

Almost 25 years ago, two more $\beta$-type proteasome subunits that are homologous to $\beta 1$ and $\beta 5$ were identified: proteasome subunit $\beta 1 \mathrm{i}$ (also known as PSMB9 and LMP2, low molecular weight protein 2) and proteasome subunit $\beta 5 \mathrm{i}$ (also known as PSMB8 and LMP7; Glynne et al., 1991; Kelly et al., 1991; Ortiz-Navarrete et al., 1991). These subunits are encoded by genes in the MHC class II region and are induced by IFN- $\gamma$ and TNF- $\alpha$ (Aki et al., 1994), leading to the designation of these subunits as "immunosubunits" and the complex they form as the "immunoproteasome" (Tanaka, 1994; Figure 2A). A third IFN- $\gamma$-inducible proteasome subunit,

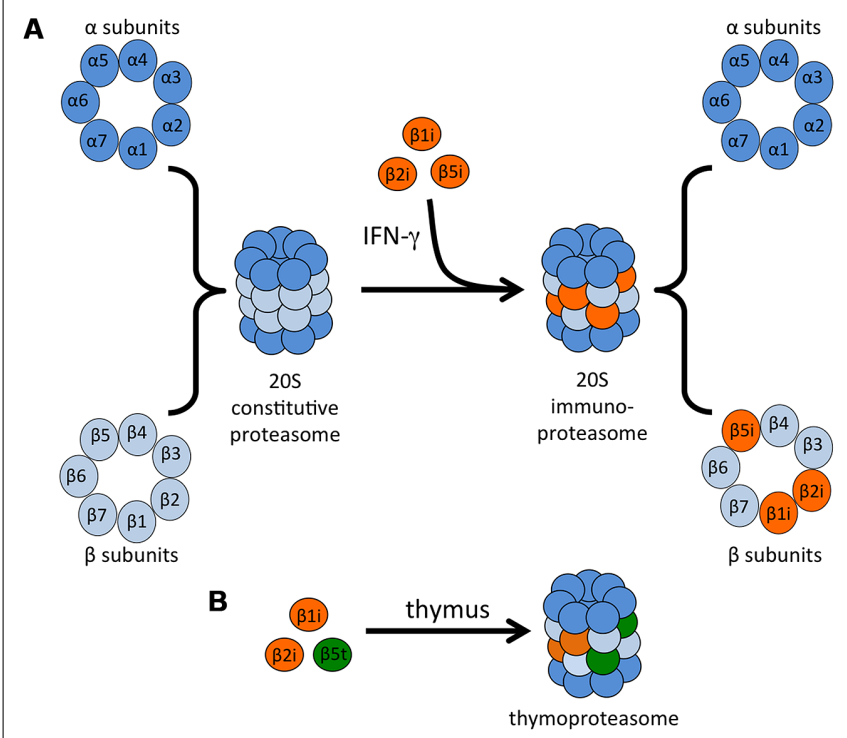

FIGURE 2 | Immunoproteasome formation and the thymoproteasome.

(A) The catalytic core of the 20S proteasome is comprised of two outer $\alpha$ rings and two inner $\beta$ rings. IFN- $\gamma$ exposure induces the synthesis of three $\beta$ "immunosubunits," which are incorporated into newly formed proteasomes in place of their constitutive counterparts to form the $20 \mathrm{~S}$ immunoproteasome. (B) In the thymus, a specialized type of proteasome is expressed in cTECs. This proteasome contains the immunosubunits $\beta 1 \mathrm{i}$ and $\beta 2 i$ as well as a cTEC-specific proteasome subunit $\beta 5 t$.

this one outside of the MHC region, was subsequently identified: proteasome subunit $\beta 2 \mathrm{i}$ (also known as PSMB10, LMP10, and MECL-1, multicatalytic endopeptidase complex-like 1), which is homologous to $\beta 2$ (Groettrup et al., 1996a; Hisamatsu et al., 1996; Nandi et al., 1996). Expression of the three immunosubunits following IFN- $\gamma$ stimulation is mediated by interferon (IFN) regulatory factor-1 (IRF-1; Chatterjee-Kishore et al., 1998; Foss and Prydz, 1999; Brucet et al., 2004; Namiki et al., 2005). Type I IFNs can also upregulate the immunoproteasome, although higher concentrations are needed to achieve the same upregulation induced by IFN- $\gamma$ (Shin et al., 2006; Freudenburg et al., 2013a,b).

An additional type of specialized proteasome, termed the thymoproteasome, was identified in cortical thymic epithelial cells (cTECs). This proteasome contains the immunosubunits $\beta 1 \mathrm{i}$ and $\beta 2 \mathrm{i}$ as well as a cTEC-specific proteasome subunit $\beta 5 \mathrm{t}$ (also known as PSMB11; Figure 2B). Expression of $\beta 5 t$ is essential for positive selection of T cells, and expression of the homologous subunits $\beta 5$ or $\beta 5$ i cannot compensate for deficiency in this specialized subunit (Murata et al., 2007; Nitta et al., 2010; Xing et al., 2013).

\section{IMMUNOPROTEASOME FORMATION AND TISSUE EXPRESSION}

Immunoproteasome assembly occurs in a cooperative manner whereby the immunosubunits interact with one another to favor the assembly of immunoproteasomes containing all three immunosubunits. This occurs even in cells that coexpress both standard and immunosubunits (Griffin et al., 1998). The immunosubunit $\beta 1 \mathrm{i}$ is incorporated more quickly than $\beta 1$, and incorporation of $\beta 2 \mathrm{i}$ depends on that of $\beta 1 \mathrm{i}$ (Groettrup et al., 1997; 
De et al., 2003). Incorporation of $\beta 5 i$ is required for the maturation (removal of the propeptides) of $\beta 1 \mathrm{i}$ and $\beta 2 \mathrm{i}$, which would otherwise prevent their catalytic activity (Groettrup et al., 1997; Griffin et al., 1998). $\beta 5 \mathrm{i}$ is the only subunit that can be incorporated into immunoproteasomes independently of the other subunits, allowing for the existence of "mixed" or intermediate proteasomes that contain both $\beta 1 \mathrm{i} / \beta 5 \mathrm{i}$ or $\beta 5 \mathrm{i}$ without other immunosubunits (Griffin et al., 1998; Kingsbury et al., 2000). Mixed proteasomes are present in some human tissue types in the absence of stimulation or inflammation, especially the liver and colon, but not the heart. They are particularly abundant ( $50 \%$ or greater of the proteasomes in cell lysates) in APCs, such as monocytes and both immature and mature DCs (Guillaume et al., 2010).

The spleen has the highest level of baseline immunoproteasome expression and activity compared to other organs (Noda et al., 2000; Ebstein et al., 2012). This makes sense given that the immunoproteasome is abundantly expressed in cells of hematopoietic origin, including professional APCs such as macrophages and B cells, found in the spleen (Frisan et al., 2000; Haorah et al., 2004). Malignant cell lines derived from B cells or multiple myeloma express high levels of immunoproteasome subunits (Frisan etal., 1998; Altun et al., 2005). There has been some disagreement regarding the regulation of immunoproteasome expression in DCs. Initial reports suggested that immature DCs constitutively express immunoproteasomes at equal levels to that of the standard proteasome. Upon maturation, immunosubunit expression is dramatically upregulated and synthesis of new proteasomes switches exclusively to immunoproteasomes (Macagno et al., 1999). Later reports showed that immunoproteasome content is unchanged or even decreased in DCs following maturation (Li etal., 2001; Macagno et al., 2001; Ossendorp et al., 2005). The disagreements regarding immunoproteasome expression in DCs may have been due to lack of immunosubunitspecific antibodies at the time of those studies. A more recent study demonstrated the presence of mostly immunoproteasomes and mixed proteasomes $(\beta 1 / \beta 2 / \beta 5 i$ and $\beta 1 i / \beta 2 / \beta 5 i)$ in immature DCs that does not change after maturation (Guillaume et al., 2010).

Constitutive expression of immunoproteasome subunits by immune cells appears to be independent of external signaling requirements, such as persistent stimulation by cytokines in vivo, because immune cells maintain their immunoproteasome expression in vitro in the absence of cytokines or other external stimuli. Rather, the high basal levels of immunoproteasome expression in immune cells are likely due to permanent activation of intracellular signaling pathways. One report demonstrated minor reductions in $\beta 1 \mathrm{i}$ and $\beta 5 \mathrm{i}$ mRNA in thymus and spleen tissue of mice lacking either type I or type II IFN receptors (Lee et al., 1999), but a second study demonstrated that the spleens of IFN- $\gamma$-deficient mice have levels of immunoproteasome protein expression similar to that of wild-type mice (Barton et al., 2002). In spleens of STAT $1^{-/-}$mice, however, mRNA and protein expression of immunoproteasome subunits is markedly reduced (Lee et al., 1999; Barton et al., 2002), suggesting that basal immunoproteasome expression does not require IFN $-\gamma$ signaling (and therefore phosphorylated STAT1), but it is at least partially dependent on non-phosphorylated STAT1. This is supported by evidence that non-phosphorylated
STAT1 and IRF1 form a complex that occupies the IFN- $\gamma$-activated sequence (GAS) elements of the $\beta 1 \mathrm{i}$ promoter to support its constitutive expression (Chatterjee-Kishore et al., 2000). There is still some basal immunoproteasome expression in spleens and thymus of STAT $1^{-/-}$mice. This may reflect equal reduction of immunoproteasome subunits in all immune cell types present in these tissues (i.e., STAT1 greatly enhances basal expression), or could be due to complete absence of immunoproteasome expression in some cell types and not others (i.e., a cell-type-specific dependence on STAT1 for basal expression).

While non-immune cells express standard proteasomes almost exclusively, immunoproteasome expression can be induced in such cells following exposure to IFN- $\gamma$. As mentioned above, type I IFNs can also upregulate the immunoproteasome, although less efficiently than IFN- $\gamma$ (Shin et al., 2006; Freudenburg et al., $2013 a, b)$. An initial report suggested that TNF- $\alpha$ could act synergistically with IFN- $\gamma$ to upregulate $\beta 5$ i expression (Hallermalm et al., 2001), implying that other proinflammatory cytokines may be capable of regulating immunoproteasome expression. However, in three murine cell lines of non-hematopoietic origin, only IFN- $\gamma$ was capable of upregulating immunoproteasome subunit expression, and there was no effect of IL- 1 , IL-4, IL-6, TNF- $\alpha$, TGF- $\beta$, IL-3, or GM-CSF treatment on immunoproteasome subunit protein levels (Barton et al., 2002). Therefore, it seems that IFN signaling is required for immunoproteasome induction in nonhematopoietic cells and that other proinflammatory cytokines cannot regulate immunoproteasome expression. There are some exceptions to reports that non-immune cells express exclusively standard proteasomes. For instance, constitutive immunoproteasome expression has been reported in immune-privileged sites that are highly unlikely to be subject to persistent cytokine stimulation, such as the eye and brain (Singh et al., 2002; Piccinini et al., 2003; Ferrington et al., 2008), suggesting a role for immunoproteasomes in non-immune processes.

\section{S AND 20S PROTEASOMES}

Proteasomes exist in many forms in cells, with different regulatory or activator cap complexes that associate with the $20 \mathrm{~S}$ core to control access to the proteolytic inner chamber (Baumeister et al., 1998). The $\alpha$ rings serve as scaffolds for the $\beta$ subunits during proteasome assembly, but they also serve as binding sites for regulatory and activator complexes. The $26 \mathrm{~S}$ proteasome, which is composed of a $20 \mathrm{~S}$ core particle and one or two 19S (also known as PA700) regulatory caps, degrades proteins in an ATP- and largely polyubiquitin-dependent manner. The 19S regulator complex recognizes and binds polyubiquitin moieties, then unfolds and feeds substrate proteins into the 20S core for degradation (Navon and Goldberg, 2001). Although 26S proteasomes preferentially degrade ubiquitinated proteins, degradation can occur without ubiquitination if the protein is first denatured (Benaroudj et al., 2001). The $26 \mathrm{~S}$ proteasome is responsible for the majority of normal protein turnover within cells. Because the $\alpha$ subunits are unchanged between different types of proteasomes, the $19 S$ regulator complex can associate with $20 S$ cores containing either standard or immunosubunits. This makes possible a number of different proteasome and immunoproteasome combinations: 20S alone, asymmetric 26S proteasomes (19S-20S), or 26S 
(19S-20S-19S), with each capable of having either the standard or immunosubunits in the $20 \mathrm{~S}$ core (Figure 3).

It was originally thought that cells have little to no free $20 \mathrm{~S}$ proteasome, and that the $20 \mathrm{~S}$ complex is incapable of acting independently of its regulators or activators (Rivett et al., 2001). Without the $19 \mathrm{~S}$ regulatory cap, the $20 \mathrm{~S}$ proteasome does not have the ability to recognize and unfold polyubiquitinated proteins. The $20 \mathrm{~S}$ core seems to exist in an autoinhibited state, where the $\mathrm{N}$-terminal tails of the $\alpha$ subunits at the openings on either end of the complex prevent substrate access to the internal proteolytic chamber (Groll et al., 2000). Binding of activator or regulatory complexes to the $20 \mathrm{~S}$ core displaces the N-terminal tails, opening a channel into the lumen of the proteasome (Whitby et al., 2000; Köhler et al., 2001). However, even in the absence of activating agents [such as heating or low detergent concentrations (Coux et al., 1996)], the $20 \mathrm{~S}$ core is capable of degrading proteins at low, albeit detectable and reproducible, rates. Degradation of proteins by the $20 \mathrm{~S}$ core probably involves partial or transient opening of the inner channel and is not an active process (Osmulski and Gaczynska, 2000, 2002; Köhler et al., 2001; Osmulski et al., 2009). Indeed, the $26 \mathrm{~S}$ proteasome and immunoproteasome hydrolyze unstructured polypeptides at rates nearly 10 -fold higher compared to $20 \mathrm{~S}$ proteasomes and immunoproteasomes (Benaroudj et al., 2001; Cascio et al., 2001; Raule et al., 2014a). However, the free $20 \mathrm{~S}$ core is capable of binding to and degrading proteins in a process that is both ATP- and ubiquitin-independent (Ciechanover, 1994; Coux etal., 1996). Rather than recognizing ubiquitin moieties, the $20 \mathrm{~S}$ proteasome has a selective preference for degradation of damaged or oxidized proteins, while the $26 \mathrm{~S}$ proteasome does not (Reinheckel et al., 1998; Davies, 2001; Pickering et al., 2010). Thus, it appears that the majority of normal protein turnover occurs through the $26 \mathrm{~S}$ proteasome, while the $20 \mathrm{~S}$ proteasome plays a specialized role in degradation of damaged or oxidized proteins. It has been suggested that oxidation may act as a marker for targeting proteins to the MHC class I pathway (Teoh and Davies, 2004). This notion, termed the PrOxI (protein oxidation and immunoproteasome) hypothesis, would represent a new mechanism of substrate generation by the proteasome and may act in concert with other pathways (such as the DRiPs pathway discussed below) to efficiently generate peptides for MHC class I presentation.

\section{PROTEASOME PROCESSING OF PEPTIDES FOR MHC CLASS I}

The changes in proteasome subunit composition from standard to immunosubunits in response to IFN- $\gamma$ stimulation alter the proteolytic activity of the complex. Purified 20S and 26S immunoproteasomes from IFN- $\gamma$-treated cells substantially increase the rate at which they cleave after hydrophobic and basic residues (Driscoll et al., 1993; Gaczynska et al., 1993; Aki et al., 1994) and decrease the rate of cleavage after acidic residues (Gaczynska et al., 1996). As the vast majority of peptides presented on MHC class I have hydrophobic or basic C-termini, the immunoproteasome is thought to generate peptides better suited to binding to MHC class I molecules compared to the constitutive proteasome and thus be more efficient at eliciting immune responses (Driscoll et al., 1993; Früh et al., 1994). Using ovalbumin (OVA) as a protein substrate, rates of degradation by $26 \mathrm{~S}$ proteasomes and immunoproteasomes, or $20 \mathrm{~S}$ proteasomes and immunoproteasomes, are indistinguishable (Cascio et al., 2001). All produce peptides of similar sizes ranging between 3 and 22 residues. 26S particles yield peptides with a mean size of $7-8$ residues, while the mean size of products from $20 \mathrm{~S}$ particles is slightly larger, at 8-9 residues (Kisselev et al., 1999). The different $\beta$ subunits therefore do not affect rates of protein degradation or peptide size, but rather seem
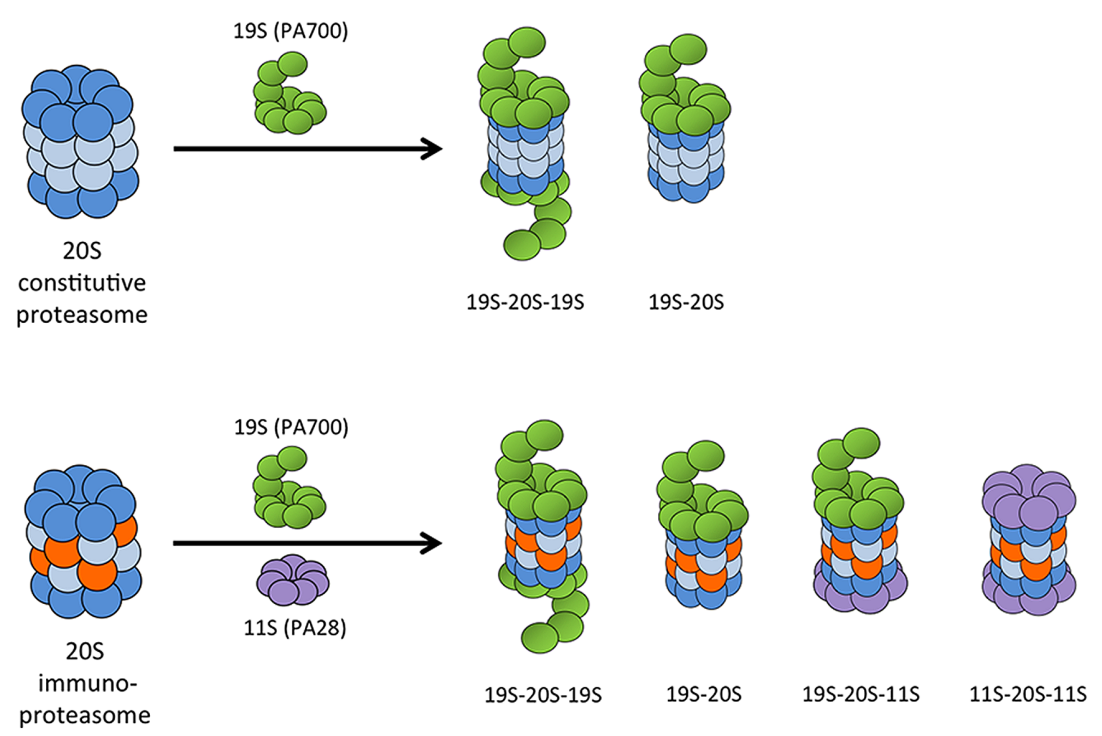

FIGURE 3 | Possible combinations of 205 proteasome core with proteasome activator complexes. The 19S (PA700) regulatory cap can associate at one or both ends of the $20 \mathrm{~S}$ proteasome core to form an asymmetric $26 \mathrm{~S}$ proteasome or a $26 \mathrm{~S}$ proteasome, respectively. The IFN- $\gamma$-induced 11S (PA28) regulatory complex can bind at the free end of a 19S-20S complex to form a hybrid proteasome, or it can associate with both ends of the $20 \mathrm{~S}$ immunoproteasome core. 
to affect the cleavage sites within a protein to generate peptides with more hydrophobic C-termini.

It was uncertain whether proteasomes cleave proteins to the exact length (8-10 residues) that would be directly loaded onto MHC class I molecules, or whether they produce larger precursors that are further cleaved by other peptidases. Some initial experiments indicated that isolated $20 \mathrm{~S}$ proteasomes could cleave larger peptides to antigenic epitopes (Niedermann et al., 1995, 1999; Lucchiari-Hartz et al., 2000). However, these experiments used short (less than 50 amino acid) precursors that are likely very different from the ubiquitinated or damaged full-length protein substrates that the proteasome would encounter under normal conditions. 20S proteasomes also release a different spectrum of products than do 26S proteasomes (Kisselev et al., 1999; Emmerich et al., 2000). A number of studies have indicated that proteasomes release $\mathrm{N}$-extended versions of antigenic peptides, which are then trimmed by aminopeptidases in the cytosol (Stoltze et al., 2000) or ER (Snyder et al., 1994; Craiu et al., 1997a). Moreover, one of these aminopeptidases, leucine aminopeptidase (LAP), is induced by IFN- $\gamma$ (Beninga et al., 1998). Following IFN- $\gamma$ treatment, cytosolic LAP activity accounted for all trimming of an $\mathrm{N}$-terminal extended version of the well-studied OVA-derived epitope SIINFEKL to the correct length.

Although immunoproteasomes degrade proteins at the same rate as standard proteasomes, immunoproteasomes generate more antigenic peptides than standard proteasomes (Cascio et al., 2001). Degradation of OVA by standard $26 \mathrm{~S}$ proteasomes isolated from muscle tissue produces SIINFEKL or an N-extended version only $6-8 \%$ of the time. When $26 \mathrm{~S}$ immunoproteasomes from the spleen are used, the percentage of peptides containing SIINFEKL at the C-terminus increases to $11 \%$. This is not due to an increase in the amount of final SIINFEKL peptide generated, as standard proteasomes and immunoproteasomes release the same amount of SIINFEKL. Instead, $20 \mathrm{~S}$ or 26S immunoproteasomes generate 2-4 times the amount of $\mathrm{N}$ extended versions of this peptide, which could be trimmed by the cytosolic enzyme LAP, compared to their standard proteasome counterparts. Therefore, it seems that the effect of IFN- $\gamma$ on antigenic peptide generation within cells is at least threefold: changes from standard to immunosubunits in the $20 \mathrm{~S}$ proteasome core directly affect C-terminal processing and generate more $\mathrm{N}$-extended versions of antigenic peptides, while induction of aminopeptidase activity in the cytosol alters N-terminal processing.

\section{IFN- $\gamma$-INDUCED PROTEASOME REGULATOR PA28}

Another protein complex induced by IFN- $\gamma$ is PA28 (also known as REG or 11S), a large regulatory complex that binds the ends of the $20 \mathrm{~S}$ proteasome in an ATP-independent manner (Figure 3). In mammals, PA28 is made of two homologous subunits, PA28 $\alpha$ (REG $\alpha$ or PSME1) and PA28 $\beta$ (REG $\beta$ or PSME2; Honoré et al., 1993; Realini et al., 1994; Ahn et al., 1995, 1996; Jiang and Monaco, 1997; Tanahashi et al., 1997; Rechsteiner et al., 2000). A third PA28 family member, PA28 $\gamma$ (also known as REG $\gamma$ or Ki antigen), is structurally related to PA28 $\alpha$ and PA28 $\beta$. PA28 $\gamma$ associates with $20 \mathrm{~S}$ proteasomes primarily in the nucleus, and unlike PA28 $\alpha / \beta$, it is not induced by IFN- $\gamma$ (Tanahashi et al., 1997). PA28 $\gamma$ does not appear to play a role in the immune response, but is involved in regulation of cell proliferation and tumorigenesis through multiple pathways (He et al., 2012; Ali et al., 2013; Li et al., 2013; LevyBarda et al., 2014). It was originally predicted that PA28 $\alpha / \beta$ either enhanced the rate of protein degradation by proteasomes or generated peptides better suited to binding to MHC class I. However, the biological functions of PA28 are still relatively unknown. PA28 does not enhance rates of protein degradation by either the standard proteasome or the immunoproteasome. In fact, PA28-20S particles degrade proteins at the same slow rate as $20 \mathrm{~S}$ particles alone (Raule et al., 2014a). PA28 appears to enhance the ability of the $20 \mathrm{~S}$ proteasome to degrade short peptide substrates, but not proteins or polyubiquitinated proteins (Dubiel et al., 1992; Ma et al., 1992). PA28 is also able to associate with asymmetric $26 \mathrm{~S}$ proteasomes (20S proteasomes with only one $19 \mathrm{~S}$ regulatory complex, usually denoted as 19S-20S) to form hybrid proteasomes (19S-20S-PA28; Figure 3; Hendil et al., 1998; Tanahashi et al., 2000; Kopp et al., 2001; Cascio et al., 2002). Hybrid proteasomes hydrolyze 3- and 4-residue peptides at faster rates than standard $26 \mathrm{~S}$ particles.

An extensive study of the molecular mechanisms of PA28 was recently undertaken by Raule et al. (2014a) who performed in vitro degradation of full-length proteins (insulin-like growth factor-1 and casein) by 20 S, 26S, and PA28 $\alpha / \beta-20$ S immunoproteasomes and analyzed the range of peptides released. Rather than increase the fraction of $8-10$ residue peptides that is generated, association of PA28 with 20S immunoproteasomes reduces it from 10\% to approximately $6 \%$ of the total, with the majority of peptides being $<6$ amino acids in length. This may occur through allosteric modification of proteasome active sites by PA28 $\alpha / \beta$. Alternatively, PA28 $\alpha / \beta$ may control the efflux of longer peptides out of the proteolytic chamber and contribute to their ongoing hydrolysis (Raule et al., 2014a; Yang and Schmidt, 2014).

Binding of PA28 to the 20 S catalytic core also appears to favor the release of a specific subset of longer peptides with an acidic $\mathrm{C}$ terminus, several of which contain the correct $\mathrm{C}$ terminal anchor residue required for binding to $\mathrm{MHC}$ class I (Raule et al., 2014a). Several studies have demonstrated that PA28 expression enhances MHC class I presentation of certain antigens (Groettrup et al., 1996b; Schwarz et al., 2000; van Hall et al., 2000; Sun etal., 2002) but not others (Murata et al., 2001). It was proposed that this small fraction of peptides specifically generated by PA28-20S immunoproteasomes may be important in stimulating an effective CD8 $\mathrm{T}$ cell response under certain pathophysiological conditions in which a ubiquitin-independent proteolytic pathway is favored. However, since the vast majority of peptides released by PA28-20S immunoproteasomes are too short to serve as MHC class I antigens, an alternative possibility is that PA28 may play a regulatory role by preventing excessive cytotoxic response against self-antigens, and decrease the risk of autoimmune reactions. A recent study demonstrated that purified PA28 $\alpha / \beta$ increases the capacity of both the constitutive $20 \mathrm{~S}$ proteasome and the immunoproteasome to selectively degrade oxidized proteins in response to hydrogen peroxideinduced oxidative stress, supporting a role for PA28 that is independent of MHC class I antigen processing (Pickering and Davies, 2012). 
Although PA28 does not stimulate proteolytic degradation under normal conditions, PA28 does increase catalytic rates of the immunoproteasome under conditions of ATP depletion (Freudenburg etal., 2013b). The implications of PA28 regulation by cellular ATP levels are unknown. Proinflammatory cytokines, such as IL-1 and IFNs, significantly decrease total cellular ATP levels (Corbett et al., 1992; Collier et al., 2006). It is possible that decreases in ATP levels that could occur during inflammatory conditions such as viral infection trigger increased association of PA28 with 20S immunoproteasomes and enhance rates of protein degradation. However, given that the majority of peptides degraded by PA28-20S proteasomes and immunoproteasomes are not suitable for binding to MHC class I, it seems unlikely that this added level of regulation is related to $\mathrm{MHC}$ class I antigen processing. It may instead be related to possible roles for PA28 in degradation of oxidized proteins or decreasing the potential for autoimmune reactions at sites of inflammation, as discussed above. If PA28 does dampen autoimmunity, then one would expect to see an increase in autoimmune responses in PA28-deficient mice after an inflammatory response. These are intriguing possibilities that bear further investigation.

\section{STRATEGIES TO STUDY IMMUNOPROTEASOME FUNCTION}

Until recently, traditional gene deletion has been the main strategy employed to study immunoproteasome function. There are numerous drawbacks to this approach. Due to cooperative assembly of immunoproteasomes, deficiency in one subunit could affect the structure and assembly of the 20S core, as well as impair binding or activity of regulatory subunits. Mice deficient in one or more of the immunosubunits since birth could develop compensatory mechanisms of proteasome or immunoproteasome assembly, leading to alteration in subunit composition that could detrimentally affect peptide processing. They could also have defects in maturation of the immune system, since the thymoproteasome (composed of $\beta 1 \mathrm{i}, \beta 2 \mathrm{i}$, and the cTEC-specific subunit $\beta 5 \mathrm{t}$ ) is important for positive selection of T cells (Murata et al., 2007). Most studies of immunoproteasome function have been undertaken with mice in which only one or two immunosubunits are deleted, rather than all three. It is possible that a standard proteasome subunit is able to compensate when only one or two immunosubunits are missing, in which case a phenotype would not be observed unless the mice are lacking all immunoproteasome activity. Therefore, caution must be taken in drawing conclusions from studies using mice deficient in one or more immunosubunits.

Small molecule peptide screens have led to the identification of inhibitors specific to immunoproteasome activity. The use of small molecule inhibitors offers several advantages over traditional gene deletion approaches, the most obvious of which is their potential for use as therapeutics. Because small molecule inhibitors are unlikely to affect the assembly or structure of the immunoproteasome, they allow for the study of how the catalytic activity of a specific subunit affects immune responses. Furthermore, these inhibitors are unlikely to affect the positive selection of $\mathrm{T}$ cells in the thymus, since most studies are undertaken in adult mice after maturation of the immune system.
The first reported immunoproteasome-specific inhibitor, PR-957 (now known as ONX 0914), inhibits $\beta 5$ i with an $\mathrm{IC}_{50}$ value of approximately $10 \mathrm{nM}$ (Muchamuel et al., 2009). ONX 0914 is 20 - to 40 -fold more selective for $\beta 5 \mathrm{i}$ than for the next two most sensitive subunits, $\beta 1 \mathrm{i}$ and $\beta 5$. A newer $\beta 5 \mathrm{i}$-specific inhibitor, PR-924, specifically targets $\beta 5 \mathrm{i}$ and has less specificity toward other subunits compared to ONX 0914 (Parlati et al., 2009). UK-101 was the first identified compound to specifically inhibit $\beta 1 \mathrm{i}$ (Ho et al., 2007; Wehenkel et al., 2012), with two more (IPSI-001 and YU-102) identified shortly thereafter (Kuhn et al., 2009; Miller etal., 2013). Leupeptin is a recently described inhibitor of the trypsin-like activity of the proteasome $(\beta 2$ and $\beta 2 \mathrm{i})$ that does not affect activity of other $\beta$ subunits (Kisselev etal., 2006; Raule etal., 2014b). There are currently no available compounds that specifically inhibit the activity of $\beta 2 \mathrm{i}$. A recent crystal structure of the murine constitutive proteasome and the immunoproteasome in complex with ONX 0914 revealed important structural differences in the binding pockets of the different subunits (Huber et al., 2012). While the crystal structures demonstrated that $\beta 1$ and $\beta 5$ have distinct substrate binding pockets that are distinct from those of their immunosubunit counterparts, the substrate binding pockets of $\beta 2$ and $\beta 2 \mathrm{i}$ are essentially identical. Therefore, it will be difficult to develop $\beta 2 \mathrm{i}$ inhibitors that do not also target its constitutive counterpart. Several other proteasome- and immunoproteasome- specific inhibitors are in development and are of significant interest as potential therapeutic agents (Miller et al., 2013).

\section{IMMUNOPROTEASOME AND ACTIVATION OF THE NF-KB PATHWAY}

The nuclear factor- $\kappa \mathrm{B}(\mathrm{NF}-\kappa \mathrm{B} / \mathrm{Rel})$ family of transcription factors plays a central role in regulation of immunity and inflammation. NF- $\mathrm{B}$ transcription factors interact as homodimers or heterodimers with other NF- $\kappa \mathrm{B}$ family members, including p65

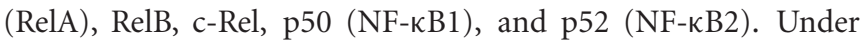
normal conditions, these factors exist in the cytoplasm in an inactive state because of interaction with inhibitory $\mathrm{I} \kappa \mathrm{B}$ proteins

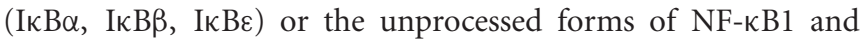

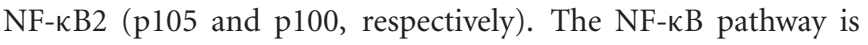
activated in response to many different stimuli, including exposure to inflammatory cytokines such as TNF- $\alpha$ or IL-1 family members (Vallabhapurapu and Karin, 2009). In the canonical or classical pathway of NF- $\kappa \mathrm{B}$ activation, the proteasome degrades $I \kappa B \alpha$, releasing the active NF- $\kappa$ B dimer (usually p65/p50) and allowing translocation to the nucleus. In the non-canonical or alternative pathway of $\mathrm{NF}-\kappa \mathrm{B}$ activation, the proteasome degrades the inhibitory portion of p105 or p100 to generate the active transcription factors $\mathrm{p} 50$ or $\mathrm{p} 52$. These transcription factors can then associate with p65, RelB, or each other to form homodimers and heterodimers. The classical and alternative NF- $\kappa \mathrm{B}$ pathways regulate distinct sets of target genes, in part because different populations of NF- $\kappa \mathrm{B}$ dimers are regulated by either I $\mathrm{B} \alpha$ degradation or p100 processing (Hayden and Ghosh, 2008).

It is widely accepted that the standard proteasome plays a crucial role in the processing of the p105 precursor of the p50 
subunit and in the degradation of IкB $\alpha$ (Palombella et al., 1994; Traenckner et al., 1994). However, a role for the immunoproteasome in NF- $\kappa \mathrm{B}$ pathway activation is controversial. Non-obese diabetic (NOD) mice were reported to have a specific defect in $\beta 1 \mathrm{i}$ production that resulted in defective activation of NF- $\kappa \mathrm{B}$ (Hayashi and Faustman, 1999). This finding has been debated, but contradictory results were likely due to different cell populations and the phenotype (non-diseased versus diseased) of NOD mice analyzed (Hayashi and Faustman, 1999; Kessler et al., 2000; Runnels etal., 2000). Nevertheless, Hayashi and Faustman (1999) did directly demonstrate impaired NF-кB activation in lymphocytes from $\beta 1 \mathrm{i}^{-/-}$mice. The T2 human lymphocyte cell line, which lacks both $\beta 1 \mathrm{i}$ and $\beta 5 \mathrm{i}$, has substantial defects in NF- $\kappa \mathrm{B}$ activation compared to the parental T1 cell line and is sensitive to TNF- $\alpha$-induced apoptosis (Hayashi and Faustman, 2000).

In support of a role for the immunoproteasome in NF- $\mathrm{B}$ activation, another study reported delayed termination of the classical NF- $\kappa$ B activation pathway and reduced activation of transcription factors associated with the alternative NF- $\kappa \mathrm{B}$ pathway in $\beta 1 \mathrm{i}^{-/-}$ mice, but not $\beta 1 \mathrm{i} / \beta 5 \mathrm{i}$ double knockout mice (Maldonado et al., 2013). B cells isolated from $\beta 1 \mathrm{i}^{-/-}$mice exhibit slightly delayed I $\kappa$ degradation, although the authors posited that defects in these mice were likely due to the presence of mixed proteasomes containing $\beta 1, \beta 2 \mathrm{i}$, and $\beta 5 \mathrm{i}$ because a $\mathrm{B}$ cell phenotype was not observed in mice lacking both $\beta 1 \mathrm{i}$ and $\beta 2 \mathrm{i}$ (Hensley et al., 2010). It is important to note that the mixed proteasomes may have abnormal function that is directly responsible for observed defects in NF- $\kappa \mathrm{B}$ activation in $\beta 1 \mathrm{i}^{-/-}$mice (discussed in more detail below). If that is the case, then the deficiencies in these cell types in $\beta 1 \mathrm{i}^{-/-}$mice are not a true reflection of deficient immunoproteasome function.

In support of this possibility, another study used two small molecule inhibitors of the immunoproteasome, UK-101 and LKS01, which target $\beta 1 \mathrm{i}$ and $\beta 5 \mathrm{i}$, respectively, to study the role of the immunoproteasome in NF- $\kappa \mathrm{B}$ activation in lung and pancreatic adenocarcinoma cells (Jang et al., 2012). Their results suggest that the catalytic activity of $\beta 1 \mathrm{i}$ and $\beta 5 \mathrm{i}$ is not required for canonical NF- $\kappa \mathrm{B}$ activation (as measured by I $\mathrm{B}$ degradation), and they support the notion that deficiencies in NF- $\kappa$ B activation in $\beta 1 \mathrm{i}^{-/-}$ mice may instead be an artifact of mixed proteasomes. One study demonstrated reduced NF- $\mathrm{B}$ activation in cardiomyocytes and B-cell-depleted splenocytes in $\beta 5 \mathrm{i}^{-/-}$mice following exposure to IFN- $\gamma$ (Opitz et al., 2011). However, because NF- $\kappa \mathrm{B}$ activation in this study was measured by assessing p50 levels in whole cell homogenates, it is unknown whether the reduced levels in $\beta 5 \mathrm{i}^{-/-}$ mice were due to impaired activation of the classical or alternative NF- $\kappa$ B pathway.

Since some studies have reported impaired activation of the alternative NF- $\kappa \mathrm{B}$ pathway in $\beta 1 \mathrm{i}^{-/-}$mice, it will be important to repeat the UK-101 and LKS01 inhibitor studies to determine whether the catalytic activity of $\beta 1 \mathrm{i}$ or $\beta 5 \mathrm{i}$ is important in the alternative pathway of NF- $\mathrm{B}$ activation by measuring p100 or p105 degradation. Additionally, it remains to be determined whether other cell types, such as those of the immune system that express the immunoproteasome constitutively, use immunoproteasome activity in the either the classical or alternative pathway of NF- $\kappa$ B activation.

\section{IMMUNOPROTEASOME FUNCTIONS IN ANTIGEN PROCESSING AND VIRAL INFECTION}

Immunoproteasome function appears to be important for a variety of host responses to viral infection, although the specific effects depend on the virus studied and the models used (summarized in Table 1). Because $\beta 1 \mathrm{i}$ and $\beta 5 \mathrm{i}$ are encoded on the MHC locus, it was originally thought that the major function of the immunoproteasome is to regulate the immune response via optimization of MHC class I peptide processing. Although proteasome activity in general is required for MHC class I antigen presentation, the immunoproteasome does not appear to be essential for that function. In fact, some epitopes are processed more efficiently by the $20 \mathrm{~S}$ proteasome than the immunoproteasome [(Morel et al., 2000; Van den Eynde and Morel, 2001) and discussed above]. However, the immunoproteasome is certainly more effective than the standard proteasome at producing many MHC class I epitopes, particularly immunodominant epitopes derived from infectious organisms. Many of the epitopes processed inefficiently by the immunoproteasome are derived from self proteins (Van den Eynde and Morel, 2001). While these epitopes may be important for generating an immune response to tumor antigens and could have implications for design of cancer vaccines, it is unlikely that they play a role in the immune response to an infectious organism.

The immunoproteasome appears to facilitate $\mathrm{T}$ cell responses that are independent of MHC class I antigen presentation. A common phenotype of immunoproteasome-deficient mice is reduced number of CD8 T cells in the spleen, supporting contributions of the immunoproteasome to T cell development or maturation (Van Kaer et al., 1994; Hensley et al., 2010; Basler et al., 2011). A number of studies have reported increased CD4/CD8 T cell ratios $\beta 2 \mathrm{i}^{-/-}$ mice (Chen et al., 2001; Caudill et al., 2006; Basler et al., 2013a), and this has recently been ascribed to a T-cell-intrinsic process that occurs independently of both thymic selection and antigen processing (Zaiss et al., 2008). T cells from $\beta 1 \mathrm{i}^{-/-}, \beta 2 \mathrm{i}^{-/-}$, or $\beta 5 \mathrm{i}^{-/-}$mice are impaired in proliferation and survival when transferred into virus-infected wild-type mice, suggesting a role for the immunoproteasome in the expansion and maintenance of T cell populations during an immune response (Chen et al., 2001; Basler et al., 2006; Moebius et al., 2010).

The immunoproteasome may also play a critical role in B cell development, as mice deficient in $\beta 1 \mathrm{i}$, but not $\beta 1 \mathrm{i} / \beta 2 \mathrm{i}$ or $\beta 5 \mathrm{i} / \beta 2 \mathrm{i}$, have reduced numbers of mature $B$ cells in the spleen (Hensley et al., 2010). These authors reported reduced survival and impaired immunoglobulin (Ig) isotype switching in B cells from $\beta 1 \mathrm{i}^{-/-}$ mice compared to wild-type B cells. A separate report was unable to recapitulate the finding of reduced $B$ cells in $\beta 1 \mathrm{i}^{-/-}$mice, and it demonstrated equivalent numbers of $\mathrm{CD} 19^{+} \mathrm{B}$ cells in the spleens of mice deficient in $\beta 1 \mathrm{i}, \beta 2 \mathrm{i}$, or both $\beta 1 \mathrm{i} / \beta 2 \mathrm{i}$ (Basler et al., 2011). $B$ cell responses were not examined in detail in that study. Therefore, the role of the immunoproteasome in B cell development or induction of a humoral response following a viral infection is still largely undefined.

The immunoproteasome, or at least the $\beta 5$ i subunit, plays a critical role in generating nearly all mouse cytomegalovirus (MCMV)derived epitopes (Hutchinson et al., 2011). Interestingly, memory "inflating" epitopes, or epitopes for which the pool of specific 
Table 1 | Contributions of immunoproteasome function during viral infection.

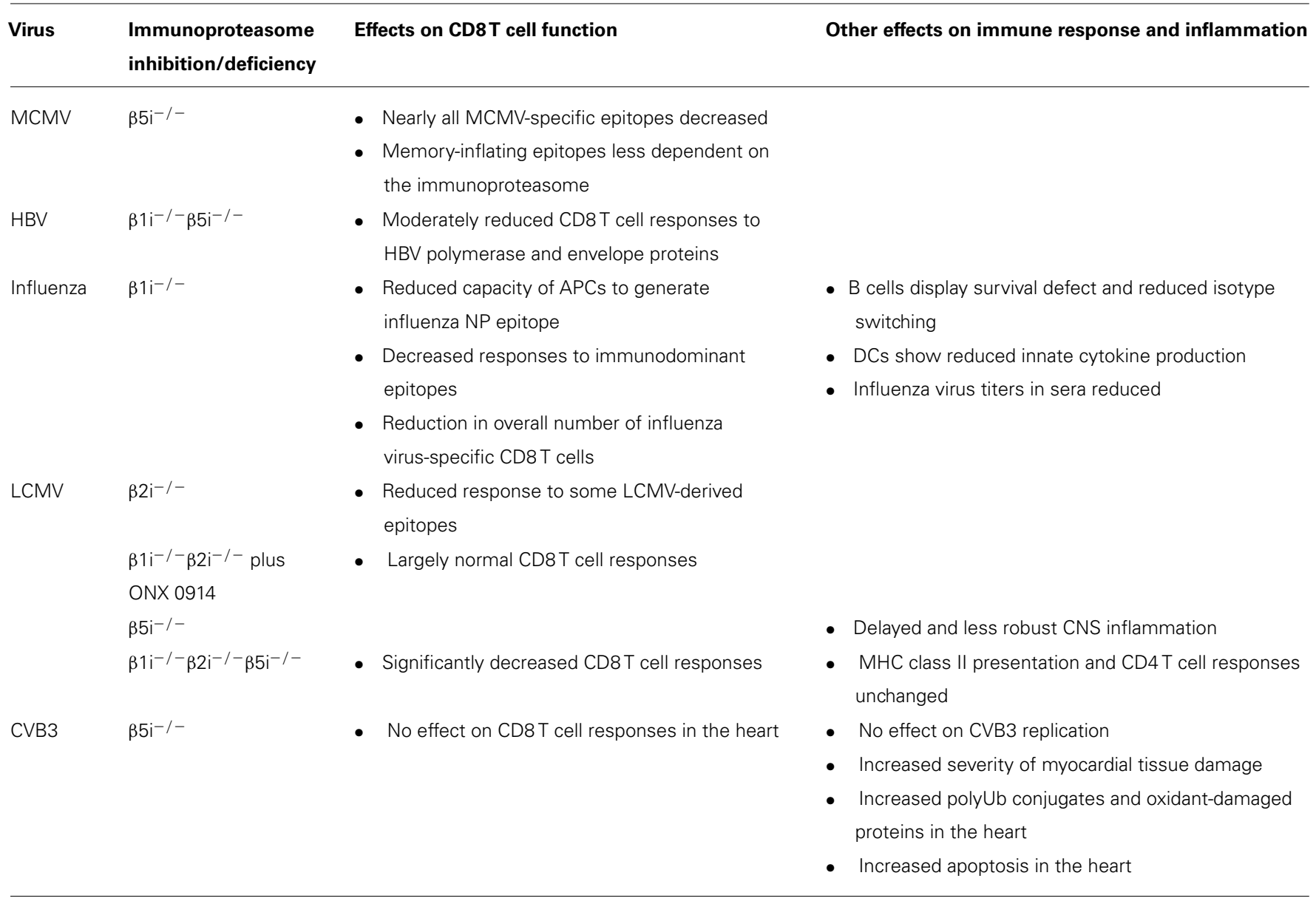

CD8 $\mathrm{T}$ cells is sustained or even increased over time, show a reduced dependence on the immunoproteasome compared to non-inflating epitopes. This suggests that immunoproteasomes play a role in stimulating immune responses during acute infection, but not during chronic MCMV infection. Although this study did not monitor the effect of $\beta 5$ i deficiency on MCMV viral loads over time, it was suggested that $\beta 5$ i deficiency likely would not have an impact on MCMV replication because neither CD8 nor MHC class I deficiency have an impact on viral loads in this model.

The immunoproteasome (subunits $\beta 1 \mathrm{i}$ and $\beta 5 \mathrm{i}$ ) moderately influences the magnitude and specificity of CD8 $\mathrm{T}$ cell responses to hepatitis B virus (HBV) polymerase and envelope proteins (Robek et al., 2007). Although type I IFNs and IFN- $\gamma$ inhibit HBV replication, the antiviral effect of IFNs occurs independently of their induction of $\beta 1 \mathrm{i}$ and $\beta 5 \mathrm{i}$.

The majority of studies examining the effect of immunoproteasome deficiency on the generation of antigenic epitopes during viral infection have been performed with influenza virus or LCMV, two well-studied viruses for which the immunodominant CD8 T cell epitopes are known. The WE strain has been the most commonly used strain for LCMV-immunoproteasome studies, while the Armstrong and clone 13 strains have been used far less frequently. It is important to consider potential differences associated with the use of different LCMV strains, which vary greatly in terms of their interactions with host immune function and their ability to persist in an infected host.

APCs from $\beta 1 \mathrm{i}^{-/-}$mice show a reduced capacity to generate an influenza virus nucleoprotein-specific epitope, while presentation of OVA-derived antigens was unaffected (Van Kaer et al., 1994). Two later studies using seven defined peptides from influenza virus showed that $\beta 1 \mathrm{i}$ (and to a lesser extent the other immunoproteasome subunits) plays a major role in establishing the immunodominance hierarchy of responding CD8 T cells (Chen et al., 2001; Pang et al., 2006). Responses to the two most immunodominant epitopes significantly decreased in $\beta 1 \mathrm{i}^{-/-}$mice. One of these was due to decreased generation of the epitope by APCs, while the other was due to reduced frequency of epitope-specific $\mathrm{T}$ cells in the CD8 $\mathrm{T}$ cell repertoire. The overall number of influenza virus-specific CD8 $\mathrm{T}$ cells was decreased in $\beta 1 \mathrm{i}^{-/-}$ mice, even when $\beta 1 i^{-/-}$CD8 $\mathrm{T}$ cells were restimulated with APCS (influenza virus-infected splenocytes) from wild-type mice. Because this defect was observed for epitopes produced equally by standard proteasomes and immunoproteasomes, it was suggested that immunoproteasomes might play a role in $\mathrm{T}$ cell activation and proliferation.

Interestingly, influenza virus titers are reduced approximately $50 \%$ in sera of $\beta 1 \mathrm{i}^{-/-}$mice. While B cells from influenza virusinfected $\beta 1 \mathrm{i}^{-/}$mice proliferate as well as those from wild-type 
mice, they display a survival defect and impaired Ig isotype switching. DCs from the same mice show reduced innate cytokine production in response to influenza virus infection (Hensley et al., 2010). The altered response of many cell types in $\beta 1 \mathrm{i}^{-/-}$mice to influenza virus is likely due to the presence of mixed proteasomes containing $\beta 2 \mathrm{i}$ and $\beta 5 \mathrm{i}$.

Care must be taken in the interpretation of results obtained using $\beta 1 \mathrm{i}^{-/-}$mice, since results cannot be attributed solely to absence of $\beta 1 \mathrm{i}$ catalytic activity. Instead, any effect may be due to dysregulated proteasome assembly and function. While mixed proteasomes containing both standard and immunosubunits have recently been isolated from wild-type mice, these mixed proteasomes contain either $\beta 1 \mathrm{i} / \beta 5 \mathrm{i}$ or just $\beta 5 \mathrm{i}$, in accordance with the rules of cooperative immunoproteasome assembly (Guillaume et al., 2010). The authors of that study were unable to detect the presence of mixed proteasomes containing $\beta 2 \mathrm{i}$, as all of the $\beta 2 \mathrm{i}$ subunits were associated with immunoproteasomes. Cooperative assembly rules should preclude formation of mixed proteasomes containing $\beta 2 \mathrm{i}$, because both $\beta 1 \mathrm{i}$ and $\beta 5 \mathrm{i}$ are required for its inclusion in the immunoproteasome. It is possible that $\beta 5 \mathrm{i}$ could compensate (perhaps partially or inefficiently) for $\beta 1 \mathrm{i}$ in the assembly process, or that $\beta 2 \mathrm{i}$ could interact with the standard $\beta 1$ subunit in the complete absence of $\beta 1 \mathrm{i}$ (as in $\beta 1 \mathrm{i}^{-/-}$ mice). This may explain the seemingly contradictory presence of mixed $\beta 2 \mathrm{i} / \beta 5 \mathrm{i}$ proteasomes in $\beta 1 \mathrm{i}^{-/-}$mice. It is doubtful that mixed proteasomes containing $\beta 2 \mathrm{i}$ exist in wild-type mice, although this has not been formally analyzed in all tissues or cell types. Mixed proteasomes (containing $\beta 1 \mathrm{i} / \beta 5 \mathrm{i}$ or $\beta 5 \mathrm{i}$ alone) are highly expressed in human immature and mature DCs. Human monocytes also contain a particularly high abundance of mixed proteasomes, up to $50 \%$ of the total proteasome content. The mixed proteasome content of B and T cells is unknown. However, the finding that mixed proteasomes are expressed at high levels in some cell types, particularly APCs, suggests that they may play an important role in shaping CD8 T cell responses. Indeed, work by Zanker etal. (2013) using mice deficient in $\beta 1 \mathrm{i}, \beta 2 \mathrm{i}$, or $\beta 2 \mathrm{i} / \beta 5 \mathrm{i}$ demonstrated that mixed proteasomes increase viral peptide diversity and broaden antiviral CD8 $\mathrm{T}$ cell responses to influenza virus.

Mice deficient in $\beta 2 \mathrm{i}$ have $\sim 20 \%$ fewer CD8 $\mathrm{T}$ cells in the spleen and reduced response to some LCMV-derived epitopes (WE strain). This is not due to impaired generation or presentation of these epitopes, but rather to either decreased precursor frequency or reduced expansion of the epitope-specific T cells, further supporting a role for the immunoproteasome in $\mathrm{T}$ cell survival or expansion rather than just antigen presentation (Basler et al., 2006). One strategy that has been employed to study mice lacking all immunoproteasome activity has been to use $\beta 1 \mathrm{i} / \beta 2 \mathrm{i}$ double knockout mice treated with the $\beta 5$ i-specific inhibitor ONX 0914 (Basler et al., 2011). Although these mice have fewer CD8 $\mathrm{T}$ cells in the spleen, and CD8 $\mathrm{T}$ cell responses to several LCMV-specific MHC class I epitopes are changed (two are increased and others are decreased; again WE strain), these double knockout mice otherwise mount largely normal CD8 T cell responses to LCMV infection. Spleen LCMV titers at 4 dpi were unchanged in immunoproteasome-deficient mice treated with ONX 0914, although it remains to be seen whether viral titers at later times (such as at $8 \mathrm{dpi}$, when CD8 T cell responses were analyzed) would be affected by lack of immunoproteasome activity. Splenocytes isolated from $\beta 1 \mathrm{i}^{-/-} \beta 2 \mathrm{i}^{-/-}$ONX 0914-treated mice and stimulated with LPS or $\alpha-\mathrm{CD} 3 / \mathrm{CD} 28$ had reduced production of IL- 6 , TNF- $\alpha$, and IFN- $\gamma$. However, this defect was observed in stimulated splenocytes from wild-type mice treated with ONX 0914 alone, suggesting a specialized function of $\beta 5 \mathrm{i}$ in promoting cytokine production that is not shared by the other immunosubunits. Because the cytokine studies in mice lacking immunoproteasome activity were performed in splenocytes stimulated ex vivo or in other models, it is unknown whether these mice display defects in cytokine production in response to LCMV or other viruses in vivo. The relatively modest effect of impaired immunoproteasome activity on the generation of LCMV-specific IFN- $\gamma^{+}$CD8 T cells suggests that overall IFN- $\gamma$ production may be unaffected. However, $\beta 1 \mathrm{i}^{-/-} \beta 2 \mathrm{i}^{-/-}$ONX 0914-treated mice may still have defects in production of other cytokines, such as IL- 6 or TNF- $\alpha$, in response to LCMV or other viruses.

Immunoproteasome subunits are transcriptionally induced in the brain following LCMV (WE strain) infection (Kremer et al., 2010). Mature immunoproteasome assembly is almost exclusively restricted to microglial-like cells, while only immunoproteasome precursors exist in astrocytes and do not exist at all in neurons or oligodendrocytes. LCMV-induced meningitis is delayed and less severe in $\beta 5 \mathrm{i}^{-/-}$mice, suggesting a role for microglial immunoproteasomes in exacerbating immunopathology. The lack of mature immunoproteasome assembly in astrocytes may be due to a posttranslational mechanism that prevents excess immunoproteasome assembly in the brain. Since cells in the CNS regenerate poorly or not at all, inhibition of immunoproteasome assembly might be a strategy to protect these cells from immunopathological destruction.

The above studies demonstrate subtle and possible organ- or virus-specific roles for the immunoproteasome during viral infection using mice deficient in only one or two immunosubunits. To assess the role of complete immunoproteasome deficiency, a recent study generated mice deficient in all three immunoproteasome subunits (triply deficient mice; Kincaid et al., 2012). This had not been performed previously because the LMP2 and LMP7 genes (encoding $\beta 1 \mathrm{i}$ and $\beta 5 \mathrm{i}$, respectively) are closely linked on the same chromosome and flank the TAP1 transporter gene, so that breeding $\beta 1 i^{-/-}$and $\beta 5 i^{-/-}$mice with each other would not likely result in a double knockout but leave TAP1 unaffected. However, Kincaid et al. (2012) used a sequential deletion strategy to first generate $\beta 1 \mathrm{i} / \beta 5 \mathrm{i}$ doubly deficient mice, which were then bred to $\beta 2 \mathrm{i}^{-/-}$mice to generate the triply deficient mice. APCs from these mice display profound defects in MHC class I antigen presentation, defects that are much more severe than those previously described in $\beta 1 \mathrm{i}, \beta 2 \mathrm{i}$, or $\beta 5 \mathrm{i}$ single knockout mice. These findings suggest that there may be functional overlap between the immunosubunits, and that the crucial role of immunoproteasomes in MHC class I antigen presentation has been obscured or underestimated by the use of mice deficient in only one immunosubunit. Triply deficient mice have an approximately 50\% reduction in surface levels of MHC class I (Kincaid et al., 2012). This is likely due to a reduction in the supply of peptides available to bind to MHC class I molecules within the cell, rather than a defect in MHC class I expression 
itself. Of note, a similar 50\% reduction of MHC class I surface expression is also observed in $\beta 5 \mathrm{i}^{-/-}$mice, but not mice lacking either $\beta 1 \mathrm{i}$ or $\beta 2 \mathrm{i}$, probably because $\beta 5 \mathrm{i}^{-/-}$mice have a more severe defect in immunoproteasome assembly than $\beta 1 \mathrm{i}^{-/-}$or $\beta 2 \mathrm{i}^{-/-}$ mice (Fehling et al., 1994). Presentation of nearly all MHC class I epitopes examined is significantly decreased in immunosubunit triply deficient mice both in vitro and in vivo. During LCMV infection (Armstrong strain), triply deficient mice display substantially weaker CD8 T cell responses than wild-type mice. This is due to defects in antigen presentation (and not to pleiotropic effects on $\mathrm{T}$ cells), because weaker $\mathrm{T}$ cell responses are also observed in wild-type $\mathrm{T}$ cells transferred into triply deficient mice. MHC class II epitope presentation and $\mathrm{CD} 4^{+} \mathrm{T}$ cell responses to LCMV are similar in wild-type and triply deficient mice, suggesting that the immunoproteasome does not affect processing of MHC class II antigens. It remains to be seen whether complete immunoproteasome deficiency (and the resulting substantially weaker CD8 T cell response) affects LCMV replication or other virus-induced inflammatory responses, such as cytokine production.

In addition to defects in antigen presentation, mice deficient in one or multiple immunoproteasome subunits have a peptide repertoire that substantially differs from wild-type mice, leading to rejection of wild-type cells when introduced into immunoproteasome-deficient mice (Toes et al., 2001; de Verteuil etal., 2010; Kincaid etal., 2012). The finding that standard proteasomes and immunoproteasomes generate such vastly different peptide repertoires has important implications. Under non-inflammatory conditions, the peptides presented on DCs (which constitutively express both standard proteasomes and immunoproteasomes) will be significantly different from the peptides displayed on non-immune parenchymal cells (which express only standard proteasomes). This implies that CD8 T cells stimulated by DCs may not efficiently recognize peptides displayed by non-immune cells until immunoproteasomes are induced in those non-immune cells by IFN. In cells that do not respond to IFN- $\gamma$ and/or do not express immunoproteasomes, such as cells infected with a virus that inhibits IFN- $\gamma$ signaling, this could suppress CD8 $\mathrm{T}$ cell responses and contribute to immune evasion. The differences in peptide repertoires produced by standard proteasomes and immunoproteasomes also have implications for acute inflammatory responses and vaccine design. During LCMV (WE strain) or Listeria monocytogenes infection, standard proteasomes in the liver are almost completely replaced by immunoproteasomes within the first 7 days of infection, leading to strongly altered proteasome activity (Khan etal., 2001). This suggests that CD8 T cell responses during the acute phase of viral and bacterial infection are primarily directed at immunoproteasome-dependent epitopes. Vaccines directed against epitopes that are poorly processed by the immunoproteasome would likely exhibit a less robust CD8 T cell response and not generate optimal protection against a particular pathogen.

Interestingly, immunoproteasomes assemble approximately four times faster than, and show greatly reduced stability relative to standard proteasomes (Heink et al., 2005). This suggests that immunoproteasome induction is a tightly regulated process, in which cytokines induced during the first few days of a viral infection signal a pressing need for immunoproteasome activity in the infected tissue. The relative instability of immunoproteasomes would provide a means for infected cells and tissues to quickly return to a normal state once immunoproteasomes are no longer needed, and it may suggest that ongoing or long-term immunoproteasome expression could actually be detrimental.

The role of the immunoproteasome during viral infection is still largely undefined, and there is evidence for organ-, virus-, and mouse strain-specific effects. Further studies are needed, especially with the newly generated triply deficient mice in which immunoproteasome activity is completely absent. Most studies examining immunoproteasome function during viral infection have focused almost exclusively on the effect of immunoproteasome subunits in shaping the repertoire of peptides available for MHC class I processing, and thus the hierarchy of CD8 T cell responses. However, the main function of the immunoproteasome during viral infection may actually be independent of the MHC class I antigen processing pathway. This is supported by the fact that $\mathrm{B}$ and $\mathrm{T}$ cells, which do not generally have a significant role as antigenpresenting cells (via MHC class I), express immunoproteasomes. A number of studies have suggested major roles for the immunoproteasome in $\mathrm{T}$ cell proliferation and survival, and there are hints from $\beta 1 \mathrm{i}^{-/-}$mice that the immunoproteasome is also important for B cell development, as described above.

Accumulating evidence suggests that the immunoproteasome is critical for the removal of oxidized proteins and adaptation to oxidative stress (Ferrington etal., 2005, 2008; Kotamraju et al., 2006; Ethen etal., 2007; Hussong etal., 2010; Pickering et al., 2010). During coxsackievirus B3 (CVB3)-induced myocarditis, $\beta 5 \mathrm{i}^{-/}$mice developed more severe myocardial tissue damage compared to wild-type mice (Opitz et al., 2011). This was not due to a direct effect on viral replication. It is interesting to note that CD8 $\mathrm{T}$ cell responses in the heart, as measured by flow cytometry and immunohistochemistry, were equivalent or even slightly enhanced in $\beta 5 \mathrm{i}^{-/-}$mice after CVB3 infection, suggesting that severe tissue damage in $\beta 5 \mathrm{i}^{-/-}$mice was not due to an alteration in the CD8 $\mathrm{T}$ cell response. Rather, cardiomyocytes and inflammatory cells from $\beta 5 i^{-/-}$mice showed increased accumulation of polyubiquitinated protein conjugates and oxidant-damaged proteins following treatment with IFN- $\gamma$. Hearts from CVB3-infected $\beta 5 \mathrm{i}^{-/}$- showed significant apoptotic cell death compared to infected wild-type mice. These findings suggest that the immunoproteasome protects cells from cytokine-induced proteotoxic stress by removing polyubiquitinated or oxidant-damaged proteins. Whether this role for the immunoproteasome is unique to CVB3-induced myocarditis or can be applied to other viral infections and disease states is unknown.

A recent study has suggested a new role for immunoproteasomes in maintaining cellular homeostasis (Raule et al., 2014b). Raule et al. (2014b) demonstrated that 26S immunoproteasomes degrade basic proteins at four- to sixfold higher rates compared to $26 \mathrm{~S}$ standard proteasomes. This effect is observed specifically for proteins with a basic isoelectric point (high content in lysine and arginine residues), and not for neutral proteins. Histones, in particular, are extremely basic. Stimulation of cells with proinflammatory cytokines induces transcription of hundreds of 
genes through multiple regulatory pathways (Boehm et al., 1997; Schroder et al., 2004). Accumulation of free histones released from these sites of transcription could result in genomic instability and transcriptional inhibition (Singh etal., 2009). The ability of immunoproteasomes to remove excess free histones more efficiently than standard proteasomes could be an important mechanism by which immunoproteasomes maintain cellular homeostasis under conditions of stress and inflammation. This also suggests an additional reason for why CVB3-infected $\beta 5 \mathrm{i}^{-/-}$ mice have increased cellular damage and apoptotic cell death in heart tissue compared to wild-type mice. Perhaps $\beta 5 \mathrm{i}^{-/-}$ mice are unable to cope with the combined accumulation of oxidant-damage proteins and excess free histones in response to cytokine-induced stress and transcriptional activation.

Few studies have examined the effect of immunoproteasome deficiency on inflammation and protection of cells from virusor cytokine-induced death during viral infection. It would be interesting to extend the studies described above with influenza, MCMV, LCMV, or other viruses in order to assess the role of the immunoproteasome in other aspects of the inflammatory response besides the generation of virus-specific epitopes for CD8 $\mathrm{T}$ cell responses.

\section{PATHOGEN INTERACTION WITH THE IMMUNOPROTEASOME}

Components of many pathogens have been shown to interact with the immunoproteasome pathway. Perhaps not surprisingly, many of these pathogens establish chronic or persistent infections. Interference with the immunoproteasome pathway may be a common mechanism by which these pathogens inhibit CD8 $\mathrm{T}$ cell responses, either during acute infection (to facilitate the establishment of persistence) or during long-term persistence for ongoing evasion of the immune system.

HIV-1 inhibits immunoproteasome function, likely by a number of mechanisms (Haorah et al., 2004). Expression of viral p24 downregulates PA28 $\beta, \beta 2 \mathrm{i}$, and $\beta 5 \mathrm{i}$ in a DC line (JAWS II) and primary DCs. Exposure of those cell lines to HIV-1 p24 leads to a decrease in antigen presentation that can be overcome by pretreatment of cells with IFN- $\gamma$ (such that the immunoproteasome is already upregulated by the time of p24 addition; Steers etal., 2009). HIV-1 Tat protein interacts with $\operatorname{six} \beta$ subunits of the standard 20S proteasome, as well as the immunosubunits $\beta 2 \mathrm{i}$ and $\beta 5 \mathrm{i}$, to decrease catalytic activity (Apcher et al., 2003). Tat also binds to two $\alpha$ subunits, $\alpha 4$ and $\alpha 7$, preventing interaction of PA28 with the 20 S core (Huang et al., 2002). The hepatitis $\mathrm{C}$ virus (HCV) non-structural protein NS3 directly binds to $\beta 5 \mathrm{i}$ and reduces immunoproteasome activity (Khu et al., 2004). Downregulation of immunoproteasome protease activity has been suggested as a mechanism by which HCV could interfere with processing of viral antigens for presentation on $\mathrm{MHC}$ class I and could avoid host immune surveillance during persistent infection.

Human adenovirus E1A interacts with the immunoproteasome subunit $\beta 2 \mathrm{i}$, but not its constitutive counterpart $\beta 2$. E1A (either in the context of adenovirus infection or via overexpression of E1A in the absence of other viral genes) also prevents IFN$\gamma$-induced upregulation of immunoproteasome subunit expression by interfering with STAT1 phosphorylation (Berhane et al.,
2011). Of note, adenoviruses have developed many other preand post-translational strategies to interfere with MHC class I processing and presentation that are independent of direct interactions between viral proteins and immunoproteasome subunits (reviewed in Blair and Blair-Zajdel, 2004).

Both human cytomegalovirus (HCMV) and MCMV inhibit IFN- $\gamma$-induced immunoproteasome formation in fibroblasts in vitro (Khan et al., 2004). Inhibition of immunoproteasome formation occurs at a pretranscriptional level, because transcriptional upregulation of PA2 $2 \alpha / \beta$, as well as all three immunosubunits, is impaired by infection. When cells are infected with an MCMV virus lacking M27, a gene that encodes a STAT2 inhibitor that interferes with IFN- $\gamma$ receptor signaling, immunoproteasome expression is no longer inhibited.

\section{CONCLUSION}

CD8 $\mathrm{T}$ cells often play significant roles during viral infection. In endogenous antigen presentation, the proteasome is crucial for the generation of antigenic peptides for binding to MHC class I and promoting CD8 $\mathrm{T}$ cell responses. The immunoproteasome is a specialized type of proteasome with altered peptide cleavage properties that is constitutively expressed in hematopoietic cells and induced in non-immune cells under conditions of inflammation. Evidence suggests that the immunoproteasome may play an important role during viral infection through regulation of CD8 T cell responses, activation of the NF- $\mathrm{B}$ pathway, and management of oxidative stress. Many viruses have mechanisms of interfering with $\mathrm{MHC}$ class I processing, including direct interaction of viral proteins with immunoproteasome subunits. It is essential to better understand the role of the immunoproteasome in different cell types, tissues, and hosts in the context of diverse inflammatory states. An improved understanding of the mechanisms of immunoproteasome function could aid in the development of vaccines and treatment strategies for viral infections.

\section{ACKNOWLEDGMENTS}

We would like to thank Megan Procario for helpful comments on the manuscript. Research in the Weinberg Laboratory is supported by NIH R01 AI083334, NIH R21 AI103452, and a University of Michigan Charles Woodson Interdisciplinary Award.

\section{REFERENCES}

Ahn, J. Y., Tanahashi, N., Akiyama, K., Hisamatsu, H., Noda, C., Tanaka, K., et al. (1995). Primary structures of two homologous subunits of PA28, a gammainterferon-inducible protein activator of the $20 \mathrm{~S}$ proteasome. FEBS Lett. 366, 37-42. doi: 10.1016/0014-5793(95)00492-R

Ahn, K., Erlander, M., Leturcq, D., Peterson, P. A., Früh, K., and Yang, Y. (1996). In vivo characterization of the proteasome regulator PA28. J. Biol. Chem. 271, 18237-18242. doi: 10.1074/jbc.271.30.18237

Aki, M., Shimbara, N., Takashina, M., Akiyama, K., Kagawa, S., Tamura, T., et al. (1994). Interferon-gamma induces different subunit organizations and functional diversity of proteasomes. J. Biochem. 115, 257-269.

Ali, A., Wang, Z., Fu, J., Ji, L., Liu, J., Li, L., et al. (2013). Differential regulation of the REG-gamma-proteasome pathway by p53/TGF-beta signalling and mutant p53 in cancer cells. Nat. Commun. 4, 1-16. doi: 10.1038/ncomms3667

Altun, M., Galardy, P. J., Shringarpure, R., Hideshima, T., Leblanc, R., Anderson, K. C., et al. (2005). Effects of PS-341 on the activity and composition of proteasomes in multiple myeloma cells. Cancer Res. 65, 7896-7901.

Apcher, G. S., Heink, S., Zantopf, D., Kloetzel, P. M., Schmid, H. P., Mayer, R. J., et al. (2003). Human immunodeficiency virus-1 Tat protein interacts with 
distinct proteasomal alpha and beta subunits. FEBS Lett. 553, 200-204. doi: 10.1016/S0014-5793(03)01025-1

Barton, L. F., Cruz, M., Rangwala, R., Deepe, G. S., and Monaco, J. J. (2002). Regulation of immunoproteasome subunit expression in vivo following pathogenic fungal infection. J. Immunol. 169, 3046-3052. doi: 10.4049/jimmunol.16 9.6.3046

Basler, M., Beck, U., Kirk, C. J., and Groettrup, M. (2011). The antiviral immune response in mice devoid of immunoproteasome activity. J. Immunol. 187, 55485557. doi: 10.4049/jimmunol.1101064

Basler, M., Kirk, C. J., and Groettrup, M. (2013a). The immunoproteasome in antigen processing and other immunological functions. Curr. Opin. Immunol. 25, 74-80. doi: 10.1016/j.coi.2012.11.004

Basler, M., Kirk, C. J., and Groettrup, M. (2013b). The immunoproteasome in antigen processing and other immunological functions. Curr. Opin. Immunol. 25, 74-80. doi: 10.1016/j.coi.2012.11.004

Basler, M., Moebius, J., Elenich, L., Groettrup, M., and Monaco, J. J. (2006). An altered T cell repertoire in MECL-1-deficient mice. J. Immunol. 176, 6665-6672. doi: 10.4049/jimmunol.176.11.6665

Baumeister, W., Walz, J., Zühl, F., and Seemüller, E. (1998). The proteasome: paradigm of a self-compartmentalizing protease. Cell 92, 367-380. doi: 10.1016/S0092-8674(00)80929-0

Benaroudj, N., Tarcsa, E., Cascio, P., and Goldberg, A. L. (2001). The unfolding of substrates and ubiquitin-independent protein degradation by proteasomes. Biochimie 83, 311-318. doi: 10.1016/S0300-9084(01)01244-5

Beninga, J., Rock, K. L., and Goldberg, A. L. (1998). Interferon-gamma can stimulate post-proteasomal trimming of the $\mathrm{N}$ terminus of an antigenic peptide by inducing leucine aminopeptidase. J. Biol. Chem. 273, 18734-18742. doi: $10.1074 /$ jbc. 273.30 .18734

Berhane, S., Aresté, C., Ablack, J. N., Ryan, G. B., Blackbourn, D. J., Mymryk, J. S., et al. (2011). Adenovirus E1A interacts directly with, and regulates the level of expression of, the immunoproteasome component MECL1. Virology 421, 149-158. doi: 10.1016/j.virol.2011.09.025

Blair, G. E., and Blair-Zajdel, M. E. (2004). Evasion of the immune system by adenoviruses. Curr. Top. Microbiol. Immunol. 273, 3-28. doi: 10.1007/978-3-66205599-1_1

Boehm, U., Klamp, T., Groot, M., and Howard, J. C. (1997). Cellular responses to interferon-gamma. Annu. Rev. Immunol. 15, 749-795. doi 10.1146/annurev.immunol.15.1.749

Brucet, M., Marqués, L., Sebastián, C., Lloberas, J., and Celada, A. (2004). Regulation of murine Tap1 and Lmp2 genes in macrophages by interferon gamma is mediated by STAT1 and IRF-1. Genes Immun. 5, 26-35. doi: 10.1038/sj.gene.63 64035

Buchmeier, M. J., Welsh, R. M., Dutko, F. J., and Oldstone, M. B. A. (1980). The virology and immunobiology of lymphocytic choriomeningitis virus infection. Adv. Immunol. 30, 275-331. doi: 10.1016/S0065-2776(08)60197-2

Cascio, P., Call, M., Petre, B. M., Walz, T., and Goldberg, A. L. (2002). Properties of the hybrid form of the $26 \mathrm{~S}$ proteasome containing both $19 \mathrm{~S}$ and PA28 complexes. EMBO J. 21, 2636-2645. doi: 10.1093/emboj/21.11.2636

Cascio, P., Hilton, C., Kisselev, A. F., Rock, K. L., and Goldberg, A. L. (2001). 26S proteasomes and immunoproteasomes produce mainly $\mathrm{N}$-extended versions of an antigenic peptide. EMBO J. 20, 2357-2366. doi: 10.1093/emboj/20.10.2357

Caudill, C. M., Jayarapu, K., Elenich, L., Monaco, J. J., Colbert, R. A., and Griffin, T. A. (2006). T cells lacking immunoproteasome subunits MECL-1 and LMP7 hyperproliferate in response to polyclonal mitogens. J. Immunol. 176, 4075-4082. doi: 10.4049/jimmunol.176.7.4075

Chatterjee-Kishore, M., Kishore, R., Hicklin, D. J., Marincola, F. M., and Ferrone, S. (1998). Different requirements for signal transducer and activator of transcription lalpha and interferon regulatory factor 1 in the regulation of low molecular mass polypeptide 2 and transporter associated with antigen processing 1 gene expression. J. Biol. Chem. 273, 16177-16183. doi: 10.1074/jbc.273.26.16177

Chatterjee-Kishore, M., Wright, K. L., Ting, J. P., and Stark, G. R. (2000). How Stat 1 mediates constitutive gene expression: a complex of unphosphorylated Stat 1 and IRF1 supports transcription of the LMP2 gene. EMBO J. 19, 4111-4122. doi: 10.1093/emboj/19.15.4111

Chen, W., Norbury, C. C., Cho, Y., Yewdell, J. W., and Bennink, J. R. (2001). Immunoproteasomes shape immunodominance hierarchies of antiviral $\mathrm{CD}^{8+} \mathrm{T}$ cells at the levels of $\mathrm{T}$ cell repertoire and presentation of viral antigens. J. Exp. Med. 193, 1319-1326. doi: 10.1084/jem.193.11.1319
Ciechanover, A. (1994). The ubiquitin-proteasome proteolytic pathway. Cell 79, 13-21. doi: 10.1016/0092-8674(94)90396-4

Collier, J. J., Fueger, P. T., Hohmeier, H. E., and Newgard, C. B. (2006). Pro- and antiapoptotic proteins regulate apoptosis but do not protect against cytokinemediated cytotoxicity in rat islets and beta-cell lines. Diabetes 55, 1398-1406. doi: $10.2337 / \mathrm{db} 05-1000$

Corbett, J. A., Wang, J. L., Hughes, J. H., Wolf, B. A., Sweetland, M. A., Lancaster, J. R., et al. (1992). Nitric oxide and cyclic GMP formation induced by interleukin 1 beta in islets of Langerhans. Evidence for an effector role of nitric oxide in islet dysfunction. Biochem. J. 287(Pt 1), 229-235.

Coux, O., Tanaka, K., and Goldberg, A. L. (1996). Structure and functions of the 20S and 26S proteasomes. Annu. Rev. Biochem. 65, 801-847. doi: 10.1146/annurev.bi.65.070196.004101

Craiu, A., Akopian, T., Goldberg, A., and Rock, K. L. (1997a). Two distinct proteolytic processes in the generation of a major histocompatibility complex class I-presented peptide. Proc. Natl. Acad. Sci. U.S.A. 94, 10850-10855. doi: 10.1073/pnas.94.20.10850

Craiu, A., Gaczynska, M., Akopian, T., Gramm, C. F., Fenteany, G., Goldberg, A. L., et al. (1997b). Lactacystin and clasto-lactacystin beta-lactone modify multiple proteasome beta-subunits and inhibit intracellular protein degradation and major histocompatibility complex class I antigen presentation. J. Biol. Chem. 272, 13437-13445. doi: 10.1074/jbc.272.20.13437

Davies, K. J. (2001). Degradation of oxidized proteins by the $20 \mathrm{~S}$ proteasome. Biochimie 83, 301-310. doi: 10.1016/S0300-9084(01)01250-0

De, M., Jayarapu, K., Elenich, L., Monaco, J. J., Colbert, R. A., and Griffin, T. A. (2003). Beta 2 subunit propeptides influence cooperative proteasome assembly. J. Biol. Chem. 278, 6153-6159. doi: 10.1074/jbc.M209292200

de Verteuil, D., Muratore-Schroeder, T. L., Granados, D. P., Fortier, M. H., Hardy, M. P., Bramoullé, A., et al. (2010). Deletion of immunoproteasome subunits imprints on the transcriptome and has a broad impact on peptides presented by major histocompatibility complex I molecules. Mol. Cell. Proteomics 9, 20342047. doi: 10.1074/mcp.M900566-MCP200

DeMartino, G. N., and Slaughter, C. A. (1999). The proteasome, a novel protease regulated by multiple mechanisms. J. Biol. Chem. 274, 22123-22126. doi: 10.1074/jbc.274.32.22123

Driscoll, J., Brown, M. G., Finley, D., and Monaco, J. J. (1993). MHC-linked LMP gene products specifically alter peptidase activities of the proteasome. Nature 365, 262-264. doi: 10.1038/365262a0

Dubiel, W., Pratt, G., Ferrell, K., and Rechsteiner, M. (1992). Purification of an 11 S regulator of the multicatalytic protease. J. Biol. Chem. 267, 22369-22377.

Ebstein, F., Kloetzel, P. M., Krüger, E., and Seifert, U. (2012b). Emerging roles of immunoproteasomes beyond MHC class I antigen processing. Cell. Mol. Life Sci. 69, 2543-2558. doi: 10.1007/s00018-012-0938-0

Ehtisham, S., Sunil-Chandra, N. P., and Nash, A. A. (1993). Pathogenesis of murine gammaherpesvirus infection in mice deficient in CD4 and CD8 T cells. J. Virol. 67, 5247-5252.

Emmerich, N. P., Nussbaum, A. K., Stevanovic, S., Priemer, M., Toes, R. E., Rammensee, H. G., et al. (2000). The human $26 \mathrm{~S}$ and $20 \mathrm{~S}$ proteasomes generate overlapping but different sets of peptide fragments from a model protein substrate. J. Biol. Chem. 275, 21140-21148. doi: 10.1074/jbc.M000740200

Ethen, C. M., Hussong, S. A., Reilly, C., Feng, X., Olsen, T. W., and Ferrington, D. A. (2007). Transformation of the proteasome with age-related macular degeneration. FEBS Lett. 581, 885-890. doi: 10.1016/j.febslet.2007.01.061

Falk, K., Rötzschke, O., Stevanović, S., Jung, G., and Rammensee, H. G. (1991). Allele-specific motifs revealed by sequencing of self-peptides eluted from MHC molecules. Nature 351, 290-296. doi: 10.1038/351290a0

Fehling, H. J., Swat, W., Laplace, C., Kühn, R., Rajewsky, K., Müller, U., et al. (1994). MHC class I expression in mice lacking the proteasome subunit LMP-7. Science 265, 1234-1237. doi: 10.1126/science.8066463

Ferrington, D. A., Husom, A. D., and Thompson, L. V. (2005). Altered proteasome structure, function, and oxidation in aged muscle. FASEB J. 19, 644-646.

Ferrington, D. A., Hussong, S. A., Roehrich, H., Kapphahn, R. J., Kavanaugh, S. M., Heuss, N. D., et al. (2008). Immunoproteasome responds to injury in the retina and brain. J. Neurochem. 106, 158-169. doi: 10.1111/j.1471-4159.2008.05345.x

Foss, G. S., and Prydz, H. (1999). Interferon regulatory factor 1 mediates the interferon-gamma induction of the human immunoproteasome subunit multicatalytic endopeptidase complex-like 1. J. Biol. Chem. 274, 35196-35202. doi: $10.1074 /$ jbc. 274.49 .35196 
Freudenburg, W., Gautam, M., Chakraborty, P., James, J., Richards, J., Salvatori, A. S., et al. (2013a). Immunoproteasome activation during early antiviral response in mouse pancreatic $\beta$-cells: new insights into auto-antigen generation in type I Diabetes? J. Clin. Cell Immunol. 4:141. doi: 10.4172/2155-9899.1000141

Freudenburg, W., Gautam, M., Chakraborty, P., James, J., Richards, J., Salvatori, A. S., et al. (2013b). Reduction in ATP levels triggers immunoproteasome activation by the $11 \mathrm{~S}$ (PA28) regulator during early antiviral response mediated by IFN $\beta$ in mouse pancreatic $\beta$-cells. PLoS ONE 8:e52408. doi: 10.1371/journal.pone.0052408

Frisan, T., Levitsky, V., and Masucci, M. G. (2000). Variations in proteasome subunit composition and enzymatic activity in B-lymphoma lines and normal B cells. Int. J. Cancer 88, 881-888. doi: 10.1002/1097-0215(20001215)88:6<881::AIDIJC7>3.0.CO;2-D

Frisan, T., Levitsky, V., Polack, A., and Masucci, M. G. (1998). Phenotype-dependent differences in proteasome subunit composition and cleavage specificity in B cell lines. J. Immunol. 160, 3281-3289.

Früh, K., Gossen, M., Wang, K., Bujard, H., Peterson, P. A., and Yang, Y. (1994). Displacement of housekeeping proteasome subunits by MHC-encoded LMPs: a newly discovered mechanism for modulating the multicatalytic proteinase complex. EMBO J. 13, 3236-3244.

Gaczynska, M., Goldberg, A. L., Tanaka, K., Hendil, K. B., and Rock, K. L. (1996). Proteasome subunits $\mathrm{X}$ and $\mathrm{Y}$ alter peptidase activities in opposite ways to the interferon-gamma-induced subunits LMP2 and LMP7. J. Biol. Chem. 271, 1727517280. doi: 10.1074/jbc.271.29.17275

Gaczynska, M., Rock, K. L., and Goldberg, A. L. (1993). Gamma-interferon and expression of MHC genes regulate peptide hydrolysis by proteasomes. Nature 365, 264-267. doi: 10.1038/365264a0

Glynne, R., Powis, S. H., Beck, S., Kelly, A., Kerr, L. A., and Trowsdale, J. (1991) A proteasome-related gene between the two $\mathrm{ABC}$ transporter loci in the class II region of the human MHC. Nature 353, 357-360. doi: 10.1038/353357a0

Griffin, T. A., Nandi, D., Cruz, M., Fehling, H. J., Kaer, L. V., Monaco, J. J., et al. (1998). Immunoproteasome assembly: cooperative incorporation of interferon gamma (IFN-gamma)-inducible subunits. J. Exp. Med. 187, 97-104. doi: 10.1084/jem.187.1.97

Groettrup, M., Kirk, C. J., and Basler, M. (2009). Proteasomes in immune cells: more than peptide producers? Nat. Rev. Immunol. 10, 73-78. doi: 10.1038/nri2687

Groettrup, M., Kraft, R., Kostka, S., Standera, S., Stohwasser, R., and Kloetzel, P. M. (1996a). A third interferon-gamma-induced subunit exchange in the $20 \mathrm{~S}$ proteasome. Eur. J. Immunol. 26, 863-869. doi: 10.1002/eji.1830260421

Groettrup, M., Soza, A., Eggers, M., Kuehn, L., Dick, T. P., Schild, H., et al. (1996b). A role for the proteasome regulator PA28alpha in antigen presentation. Nature 381, 166-168. doi: 10.1038/381166a0

Groettrup, M., Soza, A., Kuckelkorn, U., and Kloetzel, P. M. (1996c). Peptide antigen production by the proteasome: complexity provides efficiency. Immunol. Today 17, 429-435. doi: 10.1016/0167-5699(96)10051-7

Groettrup, M., Standera, S., Stohwasser, R., and Kloetzel, P. M. (1997). The subunits MECL-1 and LMP2 are mutually required for incorporation into the 20 S proteasome. Proc. Natl. Acad. Sci. U.S.A. 94, 8970-8975. doi: 10.1073/pnas.94.17.8970

Groll, M., Bajorek, M., Köhler, A., Moroder, L., Rubin, D. M., Huber, R., et al. (2000). A gated channel into the proteasome core particle. Nat. Struct. Biol. 7, 1062-1067. doi: $10.1038 / 80992$

Groll, M., Ditzel, L., Löwe, J., Stock, D., Bochtler, M., Bartunik, H. D., et al. (1997). Structure of $20 \mathrm{~S}$ proteasome from yeast at 2.4 A resolution. Nature $386,463-471$. doi: 10.1038/386463a0

Guillaume, B., Chapiro, J., Stroobant, V., Colau, D., Van Holle, B., Parvizi, G., et al. (2010). Two abundant proteasome subtypes that uniquely process some antigens presented by HLA class I molecules. Proc. Natl. Acad. Sci. U.S.A. 107, 18599-18604. doi: 10.1073/pnas.1009778107

Hallermalm, K., Seki, K., Wei, C., Castelli, C., Rivoltini, L., Kiessling, R., et al. (2001). Tumor necrosis factor-alpha induces coordinated changes in major histocompatibility class I presentation pathway, resulting in increased stability of class I complexes at the cell surface. Blood 98, 1108-1115. doi: 10.1182/blood.V98.4.1108

Haorah, J., Heilman, D., Diekmann, C., Osna, N., Donohue, T. M., Ghorpade, A., et al. (2004). Alcohol and HIV decrease proteasome and immunoproteasome function in macrophages: implications for impaired immune function during disease. Cell Immunol. 229, 139-148. doi: 10.1016/j.cellimm.2004.07.005
Hayashi, T., and Faustman, D. (1999). NOD mice are defective in proteasome production and activation of NF-kappaB. Mol. Cell. Biol. 19, 8646-8659.

Hayashi, T., and Faustman, D. (2000). Essential role of human leukocyte antigenencoded proteasome subunits in NF-kappaB activation and prevention of tumor necrosis factor-alpha-induced apoptosis. J. Biol. Chem. 275, 5238-5247. doi: 10.1074/jbc.275.7.5238

Hayden, M. S., and Ghosh, S. (2008). Shared principles in NF-kappaB signaling. Cell 132, 344-362. doi: 10.1016/j.cell.2008.01.020

He, J., Cui, L., Zeng, Y., Wang, G., Zhou, P., Yang, Y., et al. (2012). REG $\gamma$ is associated with multiple oncogenic pathways in human cancers. BMC Cancer 12:75. doi: 10.1186/1471-2407-12-75

Heink, S., Ludwig, D., Kloetzel, P. M., and Krüger, E. (2005). IFN-gammainduced immune adaptation of the proteasome system is an accelerated and transient response. Proc. Natl. Acad. Sci. U.S.A. 102, 9241-9246. doi: 10.1073/pnas.0501711102

Hendil, K. B., Khan, S., and Tanaka, K. (1998). Simultaneous binding of PA28 and PA700 activators to $20 \mathrm{~S}$ proteasomes. Biochem. J. 332(Pt 3), 749-754.

Henke, A., Huber, S., Stelzner, A., and Whitton, J. L. (1995). The role of $\mathrm{CD}^{8+} \mathrm{T}$ lymphocytes in coxsackievirus B3-induced myocarditis. J. Virol. 69, 6720-6728.

Hensley, S. E., Zanker, D., Dolan, B. P., David, A., Hickman, H. D., Embry, A. C., et al. (2010). Unexpected role for the immunoproteasome subunit LMP2 in antiviral humoral and innate immune responses. J. Immunol. 184, 4115-4122. doi: 10.4049/jimmunol.0903003

Hisamatsu, H., Shimbara, N., Saito, Y., Kristensen, P., Hendil, K. B., Fujiwara, T., et al. (1996). Newly identified pair of proteasomal subunits regulated reciprocally by interferon gamma. J. Exp. Med. 183, 1807-1816. doi: 10.1084/jem.183.4.1807

Ho, Y. K., Bargagna-Mohan, P., Wehenkel, M., Mohan, R., and Kim, K. B. (2007) LMP2-specific inhibitors: chemical genetic tools for proteasome biology. Chem. Biol. 14, 419-430. doi: 10.1016/j.chembiol.2007.03.008

Honoré, B., Leffers, H., Madsen, P., and Celis, J. E. (1993). Interferon-gamma upregulates a unique set of proteins in human keratinocytes. Molecular cloning and expression of the cDNA encoding the RGD-sequence-containing protein IGUP I-5111. Eur. J. Biochem. 218, 421-430. doi: 10.1111/j.1432-1033.1993.tb1 8392.x

Hoves, S., Trapani, J. A., and Voskoboinik, I. (2010). The battlefield of perforin/granzyme cell death pathways. J. Leukoc. Biol. 87, 237-243. doi: 10.1189/jlb.0909608

Huang, X., Seifert, U., Salzmann, U., Henklein, P., Preissner, R., Henke, W., et al. (2002). The RTP site shared by the HIV-1 Tat protein and the $11 \mathrm{~S}$ regulator subunit alpha is crucial for their effects on proteasome function including antigen processing. J. Mol. Biol. 323, 771-782. doi: 10.1016/S0022-2836(02)00998-1

Huber, E. M., Basler, M., Schwab, R., Heinemeyer, W., Kirk, C. J., Groettrup, M., et al. (2012). Immuno- and constitutive proteasome crystal structures reveal differences in substrate and inhibitor specificity. Cell 148, 727-738. doi: 10.1016/j.cell.2011.12.030

Hussong, S. A., Kapphahn, R. J., Phillips, S. L., Maldonado, M., and Ferrington, D. A. (2010). Immunoproteasome deficiency alters retinal proteasome's response to stress. J. Neurochem. 113, 1481-1490. doi: 10.1111/j.1471-4159.2010.06688.x

Hutchinson, S., Sims, S., O’Hara, G., Silk, J., Gileadi, U., Cerundolo, V., et al. (2011). A dominant role for the immunoproteasome in $\mathrm{CD} 8+\mathrm{T}$ cell responses to murine cytomegalovirus. PLoS ONE 6:e14646. doi: 10.1371/journal.pone.0014646

Jang, E. R., Lee, N. R., Han, S., Wu, Y., Sharma, L. K., Carmony, K. C., et al. (2012). Revisiting the role of the immunoproteasome in the activation of the canonical NF-кB pathway. Mol. Biosyst. 8, 2295-2302. doi: 10.1039/c2mb25125f

Jiang, H., and Monaco, J. J. (1997). Sequence and expression of mouse proteasome activator PA28 and the related autoantigen Ki. Immunogenetics 46, 93-98. doi: 10.1007/s002510050246

Kägi, D., Ledermann, B., Bürki, K., Seiler, P., Odermatt, B., Olsen, K. J., et al. (1994). Cytotoxicity mediated by $\mathrm{T}$ cells and natural killer cells is greatly impaired in perforin-deficient mice. Nature 369, 31-37. doi: 10.1038/369031a0

Kelly, A., Powis, S. H., Glynne, R., Radley, E., Beck, S., and Trowsdale, J. (1991). Second proteasome-related gene in the human MHC class II region. Nature 353, 667-668. doi: 10.1038/353667a0

Kessler, B. M., Lennon-Duménil, A. M., Shinohara, M. L., Lipes, M. A., and Ploegh, H. L. (2000). LMP2 expression and proteasome activity in NOD mice. Nat. Med. 6:1064; author reply 1065-1066.

Khan, S., Van Den Broek, M., Schwarz, K., De Giuli, R., Diener, P. A., and Groettrup, M. (2001). Immunoproteasomes largely replace constitutive proteasomes during 
an antiviral and antibacterial immune response in the liver. J. Immunol. 167, 6859-6868. doi: 10.4049/jimmunol.167.12.6859

Khan, S., Zimmermann, A., Basler, M., Groettrup, M., and Hengel, H. (2004). A cytomegalovirus inhibitor of gamma interferon signaling controls immunoproteasome induction. J. Virol. 78, 1831-1842. doi: 10.1128/JVI.78.4.1831-1842.2004

Khu, Y. L., Tan, Y. J., Lim, S. G., Hong, W., and Goh, P. Y. (2004). Hepatitis $\mathrm{C}$ virus non-structural protein NS3 interacts with LMP7, a component of the immunoproteasome, and affects its proteasome activity. Biochem. J. 384, 401-409. doi: 10.1042/BJ20040858

Kincaid, E. Z., Che, J. W., York, I., Escobar, H., Reyes-Vargas, E., Delgado, J. C., et al. (2012). Mice completely lacking immunoproteasomes show major changes in antigen presentation. Nat. Immunol. 13, 129-135. doi: 10.1038/ni.2203

Kingsbury, D. J., Griffin, T. A., and Colbert, R. A. (2000). Novel propeptide function in $20 \mathrm{~S}$ proteasome assembly influences beta subunit composition. J. Biol. Chem. 275, 24156-24162. doi: 10.1074/jbc.M001742200

Kisselev, A. F., Akopian, T. N., Woo, K. M., and Goldberg, A. L. (1999). The sizes of peptides generated from protein by mammalian 26 and $20 \mathrm{~S}$ proteasomes. Implications for understanding the degradative mechanism and antigen presentation. J. Biol. Chem. 274, 3363-3371. doi: 10.1074/jbc.274.6.3363

Kisselev, A. F., Callard, A., and Goldberg, A. L. (2006). Importance of the different proteolytic sites of the proteasome and the efficacy of inhibitors varies with the protein substrate. J. Biol. Chem. 281, 8582-8590. doi: 10.1074/jbc.M5090 43200

Köhler, A., Cascio, P., Leggett, D. S., Woo, K. M., Goldberg, A. L., and Finley, D. (2001). The axial channel of the proteasome core particle is gated by the Rpt2 ATPase and controls both substrate entry and product release. Mol. Cell 7, 1143-1152. doi: 10.1016/S1097-2765(01)00274-X

Kopp, F., Dahlmann, B., and Kuehn, L. (2001). Reconstitution of hybrid proteasomes from purified PA700-20 S complexes and PA28alphabeta activator: ultrastructure and peptidase activities. J. Mol. Biol. 313, 465-471. doi: 10.1006/jmbi. 2001.5063

Kotamraju, S., Matalon, S., Matsunaga, T., Shang, T., Hickman-Davis, J. M., and Kalyanaraman, B. (2006). Upregulation of immunoproteasomes by nitric oxide: potential antioxidative mechanism in endothelial cells. Free Radic. Biol. Med. 40, 1034-1044. doi: 10.1016/j.freeradbiomed.2005.10.052

Kremer, M., Henn, A., Kolb, C., Basler, M., Moebius, J., Guillaume, B., et al. (2010) Reduced immunoproteasome formation and accumulation of immunoproteasomal precursors in the brains of lymphocytic choriomeningitis virus-infected mice. J. Immunol. 185, 5549-5560. doi: 10.4049/jimmunol.1001517

Kuhn, D. J., Hunsucker, S. A., Chen, Q., Voorhees, P. M., Orlowski, M., and Orlowski, R. Z. (2009). Targeted inhibition of the immunoproteasome is a potent strategy against models of multiple myeloma that overcomes resistance to conventional drugs and nonspecific proteasome inhibitors. Blood 113, 4667-4676. doi: 10.1182/blood-2008-07-171637

Lang, P. A., Contaldo, C., Georgiev, P., El-Badry, A. M., Recher, M., Kurrer, M., et al. (2008). Aggravation of viral hepatitis by platelet-derived serotonin. Nat. Med. 14 756-761. doi: 10.1038/nm1780

Lee, C. K., Gimeno, R., and Levy, D. E. (1999). Differential regulation of constitutive major histocompatibility complex class I expression in $\mathrm{T}$ and $\mathrm{B}$ lymphocytes. J. Exp. Med. 190, 1451-1464. doi: 10.1084/jem.190.10.1451

Levy-Barda, A., Lerenthal, Y., Davis, A. J., Chung, Y. M., Essers, J., Shao, Z., et al. (2014). Involvement of the nuclear proteasome activator PA28 $\gamma$ in the cellular response to DNA double-strand breaks. Cell Cycle 10, 4300-4310. doi: $10.4161 /$ cc.10.24.18642

Li, J., Schuler-Thurner, B., Schuler, G., Huber, C., and Seliger, B. (2001). Bipartite regulation of different components of the MHC class I antigen-processing machinery during dendritic cell maturation. Int. Immunol. 13, 1515-1523. doi: 10.1093/intimm/13.12.1515

Li, L., Zhao, D., Wei, H., Yao, L., Dang, Y., Amjad, A., et al. (2013). REG $\gamma$ deficiency promotes premature aging via the casein kinase 1 pathway. Proc. Natl. Acad. Sci. U.S.A. 110, 11005-11010. doi: 10.1073/pnas.1308497110

Lucchiari-Hartz, M., Van Endert, P. M., Lauvau, G., Maier, R., Meyerhans, A., Mann, D., et al. (2000). Cytotoxic T lymphocyte epitopes of HIV-1 Nef: generation of multiple definitive major histocompatibility complex class I ligands by proteasomes. J. Exp. Med. 191, 239-252. doi: 10.1084/jem.191.2.239

Ma, C. P., Slaughter, C. A., and Demartino, G. N. (1992). Identification, purification, and characterization of a protein activator (PA28) of the $20 \mathrm{~S}$ proteasome (macropain). J. Biol. Chem. 267, 10515-10523.
Macagno, A., Gilliet, M., Sallusto, F., Lanzavecchia, A., Nestle, F. O., and Groettrup, M. (1999). Dendritic cells up-regulate immunoproteasomes and the proteasome regulator PA28 during maturation. Eur. J. Immunol. 29, 4037-4042. doi: 10.1002/(SICI)1521-4141(199912)29:12\&\#60;4037::AIDIMMU4037\&\#62;3.0.CO;2-T

Macagno, A., Kuehn, L., De Giuli, R., and Groettrup, M. (2001). Pronounced upregulation of the PA28alpha/beta proteasome regulator but little increase in the steady-state content of immunoproteasome during dendritic cell maturation. Eur. J. Immunol. 31, 3271-3280. doi: 10.1002/1521-4141(200111)31:11<3271::AIDIMMU3271>3.0.CO;2-2

Maldonado, M., Kapphahn, R. J., Terluk, M. R., Heuss, N. D., Yuan, C., Gregerson, D. S., et al. (2013). Immunoproteasome deficiency modifies the alternative pathway of NFKB signaling. PLoS ONE 8:e56187. doi: 10.1371/journal.pone.0056187 Miller, Z., Ao, L., Kim, K. B., and Lee, W. (2013). Inhibitors of the immunoproteasome: current status and future directions. Curr. Pharm. Des. 19, 4140-4151. doi: $10.2174 / 1381612811319220018$

Moebius, J., Van Den Broek, M., Groettrup, M., and Basler, M. (2010). Immunoproteasomes are essential for survival and expansion of $\mathrm{T}$ cells in virus-infected mice. Eur. J. Immunol. 40, 3439-3449. doi: 10.1002/eji.201040620

Morel, S., Lévy, F., Burlet-Schiltz, O., Brasseur, F., Probst-Kepper, M., Peitrequin, A. L., et al. (2000). Processing of some antigens by the standard proteasome but not by the immunoproteasome results in poor presentation by dendritic cells. Immunity 12, 107-117. doi: 10.1016/S1074-7613(00)80163-6

Muchamuel, T., Basler, M., Aujay, M. A., Suzuki, E., Kalim, K. W., Lauer, C., et al. (2009). A selective inhibitor of the immunoproteasome subunit LMP7 blocks cytokine production and attenuates progression of experimental arthritis. Nat. Med. 15, 781-787. doi: 10.1038/nm.1978

Müllbacher, A., Hla, R. T., Museteanu, C., and Simon, M. M. (1999). Perforin is essential for control of ectromelia virus but not related poxviruses in mice. J. Virol. 73, 1665-1667.

Murata, S., Sasaki, K., Kishimoto, T., Niwa, S. I., Hayashi, H., Takahama, Y., et al. (2007). Regulation of $\mathrm{CD}^{8+} \mathrm{T}$ cell development by thymus-specific proteasomes. Science 316, 1349-1353. doi: 10.1126/science.1141915

Murata, S., Udono, H., Tanahashi, N., Hamada, N., Watanabe, K., Adachi, K., etal. (2001). Immunoproteasome assembly and antigen presentation in mice lacking both PA28alpha and PA28beta. EMBO J. 20, 5898-5907. doi: 10.1093/emboj/20.21.5898

Namiki, S., Nakamura, T., Oshima, S., Yamazaki, M., Sekine, Y., Tsuchiya, K., et al. (2005). IRF-1 mediates upregulation of LMP7 by IFN-gamma and concerted expression of immunosubunits of the proteasome. FEBS Lett. 579, 2781-2787. doi: 10.1016/j.febslet.2005.04.012

Nandi, D., Jiang, H., and Monaco, J. J. (1996). Identification of MECL-1 (LMP10) as the third IFN-gamma-inducible proteasome subunit. J. Immunol. 156, 2361-2364.

Navon, A., and Goldberg, A. L. (2001). Proteins are unfolded on the surface of the ATPase ring before transport into the proteasome. Mol. Cell. 8, 1339-1349. doi: 10.1016/S1097-2765(01)00407-5

Neefjes, J. J., Momburg, F., and Hämmerling, G. J. (1993). Selective and ATPdependent translocation of peptides by the MHC-encoded transporter. Science 261, 769-771. doi: 10.1126/science.8342042

Niedermann, G., Butz, S., Ihlenfeldt, H. G., Grimm, R., Lucchiari, M., Hoschützky, H., et al. (1995). Contribution of proteasome-mediated proteolysis to the hierarchy of epitopes presented by major histocompatibility complex class I molecules. Immunity 2, 289-299. doi: 10.1016/1074-7613(95)90053-5

Niedermann, G., Geier, E., Lucchiari-Hartz, M., Hitziger, N., Ramsperger, A., and Eichmann, K. (1999). The specificity of proteasomes: impact on MHC class I processing and presentation of antigens. Immunol. Rev. 172, 29-48. doi: 10.1111/j.1600-065X.1999.tb01354.x

Nitta, T., Murata, S., Sasaki, K., Fujii, H., Ripen, A. M., Ishimaru, N., et al. (2010). Thymoproteasome shapes immunocompetent repertoire of $\mathrm{CD}^{8+} \mathrm{T}$ cells. Immunity 32, 29-40. doi: 10.1016/j.immuni.2009.10.009

Noda, C., Tanahashi, N., Shimbara, N., Hendil, K. B., and Tanaka, K. (2000). Tissue distribution of constitutive proteasomes, immunoproteasomes, and PA28 in rats. Biochem. Biophys. Res. Commun. 277, 348-354. doi: 10.1006/bbrc.2000.3676

Opitz, E., Koch, A., Klingel, K., Schmidt, F., Prokop, S., Rahnefeld, A., et al. (2011). Impairment of immunoproteasome function by $\beta 5 i$ LMP7 subunit deficiency results in severe enterovirus myocarditis. PLoS Pathog. 7:e1002233. doi: 10.1371/journal.ppat.1002233 
Ortiz-Navarrete, V., Seelig, A., Gernold, M., Frentzel, S., Kloetzel, P. M., and Hämmerling, G. J. (1991). Subunit of the '20S' proteasome (multicatalytic proteinase) encoded by the major histocompatibility complex. Nature 353, 662-664. doi: $10.1038 / 353662 \mathrm{a} 0$

Osmulski, P. A., and Gaczynska, M. (2000). Atomic force microscopy reveals two conformations of the $20 \mathrm{~S}$ proteasome from fission yeast. J. Biol. Chem. 275 13171-13174. doi: 10.1074/jbc.C901035199

Osmulski, P. A., and Gaczynska, M. (2002). Nanoenzymology of the 20S proteasome: proteasomal actions are controlled by the allosteric transition. Biochemistry 41, 7047-7053. doi: 10.1021/bi0159130

Osmulski, P. A., Hochstrasser, M., and Gaczynska, M. (2009). A tetrahedral transition state at the active sites of the $20 \mathrm{~S}$ proteasome is coupled to opening of the alpha-ring channel. Structure 17, 1137-1147. doi: 10.1016/j.str.200 9.06.011

Ossendorp, F., Fu, N., Camps, M., Granucci, F., Gobin, S. J. P., Van Den Elsen, P. J., et al. (2005). Differential expression regulation of the alpha and beta subunits of the PA28 proteasome activator in mature dendritic cells. J. Immunol. 174 7815-7822. doi: 10.4049/jimmunol.174.12.7815

Palombella, V. J., Rando, O. J., Goldberg, A. L., and Maniatis, T. (1994). The ubiquitin-proteasome pathway is required for processing the NF-kappa B1 precursor protein and the activation of NF-kappa B. Cell 78, 773-785. doi: 10.1016/S0092-8674(94)90482-0

Pang, K. C., Sanders, M. T., Monaco, J. J., Doherty, P. C., Turner, S. J., and Chen, W. (2006). Immunoproteasome subunit deficiencies impact differentially on two immunodominant influenza virus-specific $\mathrm{CD}^{8+} \mathrm{T}$ cell responses. J. Immunol. 177, 7680-7688. doi: 10.4049/jimmunol.177.11.7680

Parlati, F., Lee, S. J., Aujay, M., Suzuki, E., Levitsky, K., Lorens, J. B., et al (2009). Carfilzomib can induce tumor cell death through selective inhibition of the chymotrypsin-like activity of the proteasome. Blood 114, 3439-3447. doi: 10.1182/blood-2009-05-223677

Piccinini, M., Mostert, M., Croce, S., Baldovino, S., Papotti, M., and Rinaudo, M. T. (2003). Interferon-gamma-inducible subunits are incorporated in human brain 20 S proteasome. J. Neuroimmunol. 135, 135-140. doi: 10.1016/S01655728(02)00439-3

Pickering, A. M., and Davies, K. J. A. (2012). Differential roles of proteasome and immunoproteasome regulators $\mathrm{Pa} 28 \alpha \beta, \mathrm{Pa} 28 \gamma$ and $\mathrm{Pa} 200$ in the degradation of oxidized proteins. Arch. Biochem. Biophys. 523, 181-190. doi: 10.1016/j.abb.2012.04.018

Pickering, A. M., Koop, A. L., Teoh, C. Y., Ermak, G., Grune, T., and Davies, K. J. A. (2010). The immunoproteasome, the $20 \mathrm{~S}$ proteasome and the PA28 $\alpha \beta$ proteasome regulator are oxidative-stress-adaptive proteolytic complexes. Biochem. J. 432, 585-594. doi: 10.1042/BJ20100878

Raule, M., Cerruti, F., Benaroudj, N., Migotti, R., Kikuchi, J., Bachi, A., et al (2014a). PA28 $\alpha \beta$ reduces size and increases hydrophilicity of 20 S immunoproteasome peptide products. Chem. Biol. 21, 470-480. doi: 10.1016/j.chembiol.2014. 02.006

Raule, M., Cerruti, F., and Cascio, P. (2014b). Enhanced rate of degradation of basic proteins by 26 S immunoproteasomes. Biochim. Biophys. Acta 1843, 1942-1947. doi: 10.1016/j.bbamcr.2014.05.005

Realini, C., Dubiel, W., Pratt, G., Ferrell, K., and Rechsteiner, M. (1994). Molecular cloning and expression of a gamma-interferon-inducible activator of the multicatalytic protease. J. Biol. Chem. 269, 20727-20732.

Rechsteiner, M., Realini, C., and Ustrell, V. (2000). The proteasome activator $11 \mathrm{~S}$ REG (PA28) and class I antigen presentation. Biochem. J. 345(Pt 1), 1-15. doi 10.1042/0264-6021:3450001

Reinheckel, T., Sitte, N., Ullrich, O., Kuckelkorn, U., Davies, K. J., and Grune, T. (1998). Comparative resistance of the $20 \mathrm{~S}$ and $26 \mathrm{~S}$ proteasome to oxidative stress. Biochem. J. 335(Pt 3), 637-642.

Rivett, A. J., Bose, S., Brooks, P., and Broadfoot, K. I. (2001). Regulation of proteasome complexes by gamma-interferon and phosphorylation. Biochimie 83 , 363-366. doi: 10.1016/S0300-9084(01)01249-4

Robek, M. D., Garcia, M. L., Boyd, B. S., and Chisari, F. V. (2007). Role of immunoproteasome catalytic subunits in the immune response to hepatitis B virus. J. Virol. 81, 483-491. doi: 10.1128/JVI.01779-06

Rock, K. L., Gramm, C., Rothstein, L., Clark, K., Stein, R., Dick, L., et al. (1994). Inhibitors of the proteasome block the degradation of most cell proteins and the generation of peptides presented on MHC class I molecules. Cell 78, 761-771. doi: 10.1016/S0092-8674(94)90462-6
Runnels, H. A., Watkins, W. A., and Monaco, J. J. (2000). LMP2 expression and proteasome activity in NOD mice. Nat. Med. 6, 1064-1065; author reply 10651066. doi: $10.1038 / 80349$

Russell, J. H., and Ley, T. J. (2002). Lymphocyte-mediated cytotoxicity. Annu. Rev. Immunol. 20, 323-370. doi: 10.1146/annurev.immunol.20.100201.131730

Schroder, K., Hertzog, P. J., Ravasi, T., and Hume, D. A. (2004). Interferon-gamma: an overview of signals, mechanisms and functions. J. Leukoc. Biol. 75, 163-189. doi: $10.1189 /$ jlb.0603252

Schwarz, K., Van Den Broek, M., Kostka, S., Kraft, R., Soza, A., Schmidtke, G., et al. (2000). Overexpression of the proteasome subunits LMP2, LMP7, and MECL1, but not PA28 alpha/beta, enhances the presentation of an immunodominant lymphocytic choriomeningitis virus T cell epitope. J. Immunol. 165, 768-778. doi: 10.4049/jimmunol.165.2.768

Shin, E. C., Seifert, U., Kato, T., Rice, C. M., Feinstone, S. M., Kloetzel, P. M., et al. (2006). Virus-induced type I IFN stimulates generation of immunoproteasomes at the site of infection. J. Clin. Invest. 116, 3006-3014. doi: 10.1172/JCI 29832

Singh, R. K., Kabbaj, M. H. M., Paik, J., and Gunjan, A. (2009). Histone levels are regulated by phosphorylation and ubiquitylation-dependent proteolysis. Nat. Cell Biol. 11, 925-933. doi: 10.1038/ncb1903

Singh, S., Awasthi, N., Egwuagu, C. E., and Wagner, B. J. (2002). Immunoproteasome expression in a nonimmune tissue, the ocular lens. Arch. Biochem. Biophys. 405, 147-153. doi: 10.1016/S0003-9861(02)00341-7

Snyder, H. L., Yewdell, J. W., and Bennink, J. R. (1994). Trimming of antigenic peptides in an early secretory compartment. J. Exp. Med. 180, 2389-2394. doi: 10.1084/jem.180.6.2389

Steers, N. J., Peachman, K. K., Mcclain, S. R., Alving, C. R., and Rao, M. (2009). Human immunodeficiency virus type $1 \mathrm{Gag}$ p24 alters the composition of immunoproteasomes and affects antigen presentation. J. Virol. 83, 7049-7061. doi: 10.1128/JVI.00327-09

Stoltze, L., Schirle, M., Schwarz, G., Schröter, C., Thompson, M. W., Hersh, L. B., et al. (2000). Two new proteases in the MHC class I processing pathway. Nat. Immunol. 1, 413-418. doi: 10.1038/80852

Sun, Y., Sijts, A. J., Song, M., Janek, K., Nussbaum, A. K., Kral, S., et al. (2002). Expression of the proteasome activator PA28 rescues the presentation of a cytotoxic $T$ lymphocyte epitope on melanoma cells. Cancer Res. 62, 2875-2882.

Tanahashi, N., Murakami, Y., Minami, Y., Shimbara, N., Hendil, K. B., and Tanaka, K. (2000). Hybrid proteasomes. Induction by interferon-gamma and contribution to ATP-dependent proteolysis. J. Biol. Chem. 275, 14336-14345. doi: 10.1074/jbc.275.19.14336

Tanahashi, N., Yokota, K., Ahn, J. Y., Chung, C. H., Fujiwara, T., Takahashi, E., et al. (1997). Molecular properties of the proteasome activator PA28 family proteins and gamma-interferon regulation. Genes Cells 2, 195-211. doi: 10.1046/j.13652443.1997.d01-308.x

Tanaka, K. (1994). Role of proteasomes modified by interferon-gamma in antigen processing. J. Leukoc. Biol. 56, 571-575.

Tanaka, K. (1995). Molecular biology of proteasomes. Mol. Biol. Rep. 21, 21-26. doi: 10.1007/BF00990966

Teoh, C. Y., and Davies, K. J. A. (2004). Potential roles of protein oxidation and the immunoproteasome in MHC class I antigen presentation: the 'PrOxI' hypothesis Arch. Biochem. Biophys. 423, 88-96. doi: 10.1016/j.abb.2003.12.001

Toes, R. E., Nussbaum, A. K., Degermann, S., Schirle, M., Emmerich, N. P., Kraft, M. et al. (2001). Discrete cleavage motifs of constitutive and immunoproteasomes revealed by quantitative analysis of cleavage products. J. Exp. Med. 194, 1-12. doi: 10.1084/jem.194.1.1

Traenckner, E. B., Wilk, S., and Baeuerle, P. A. (1994). A proteasome inhibitor prevents activation of NF-kappa B and stabilizes a newly phosphorylated form of I kappa B-alpha that is still bound to NF-kappa B. EMBO J. 13, 5433-5441.

Unno, M., Mizushima, T., Morimoto, Y., Tomisugi, Y., Tanaka, K., Yasuoka, N., et al. (2002). The structure of the mammalian 20S proteasome at 2.75 A resolution. Structure 10, 609-618. doi: 10.1016/S0969-2126(02)00748-7

Vallabhapurapu, S., and Karin, M. (2009). Regulation and function of NF-kappaB transcription factors in the immune system. Annu. Rev. Immunol. 27, 693-733. doi: 10.1146/annurev.immunol.021908.132641

Van den Eynde, B. J., and Morel, S. (2001). Differential processing of classI-restricted epitopes by the standard proteasome and the immunoproteasome. Curr. Opin. Immunol. 13, 147-153. doi: 10.1016/S0952-7915(00) 00197-7 
van Hall, T., Sijts, A., Camps, M., Offringa, R., Melief, C., Kloetzel, P. M., et al. (2000). Differential influence on cytotoxic T lymphocyte epitope presentation by controlled expression of either proteasome immunosubunits or PA28. J. Exp. Med. 192, 483-494. doi: 10.1084/jem.192.4.483

Van Kaer, L., Ashton-Rickardt, P. G., Eichelberger, M., Gaczynska, M., Nagashima, K., Rock, K. L., et al. (1994). Altered peptidase and viral-specific T cell response in LMP2 mutant mice. Immunity 1, 533-541. doi: 10.1016/1074-7613(94) 90043-4

Walsh, C. M., Matloubian, M., Liu, C. C., Ueda, R., Kurahara, C. G., Christensen, J. L., et al. (1994). Immune function in mice lacking the perforin gene. Proc. Natl. Acad. Sci. U.S.A. 91, 10854-10858. doi: 10.1073/pnas.91.23.10854

Warnatsch, A., Bergann, T., and Krüger, E. (2013). Oxidation matters: the ubiquitin proteasome system connects innate immune mechanisms with MHC class I antigen presentation. Mol. Immunol. 55, 106-109. doi: 10.1016/j.molimm.2012.10.007

Wehenkel, M., Ban, J. O., Ho, Y. K., Carmony, K. C., Hong, J. T., and Kim, K. B. (2012). A selective inhibitor of the immunoproteasome subunit LMP2 induces apoptosis in PC-3 cells and suppresses tumour growth in nude mice. Br. J. Cancer 107, 53-62. doi: 10.1038/bjc.2012.243

Whitby, F. G., Masters, E. I., Kramer, L., Knowlton, J. R., Yao, Y., Wang, C. C., et al. (2000). Structural basis for the activation of $20 \mathrm{~S}$ proteasomes by $11 \mathrm{~S}$ regulators. Nature 408, 115-120. doi: 10.1038/35040607

Xing, Y., Jameson, S. C., and Hogquist, K. A. (2013). Thymoproteasome subunit- $\beta 5 \mathrm{~T}$ generates peptide-MHC complexes specialized for positive selection. Proc. Natl. Acad. Sci. U.S.A. 110, 6979-6984. doi: 10.1073/pnas.12222 44110
Yang, C., and Schmidt, M. (2014). Cutting through complexity: the proteolytic properties of alternate immunoproteasome complexes. Chem. Biol. 21, 435-436. doi: 10.1016/j.chembiol.2014.04.001

Zaiss, D. M. W., De Graaf, N., and Sijts, A. J. (2008). The proteasome immunosubunit multicatalytic endopeptidase complex-like 1 is a T-cell-intrinsic factor influencing homeostatic expansion. Infect. Immun. 76, 1207-1213. doi: 10.1128/IAI.01134-07 Zanker, D., Waithman, J., Yewdell, J. W., and Chen, W. (2013). Mixed proteasomes function to Increase viral peptide diversity and broaden antiviral $\mathrm{CD}^{8+} \mathrm{T}$ cell responses. J. Immunol. 191, 52-59. doi: 10.4049/jimmunol.1300802

Conflict of Interest Statement: The authors declare that the research was conducted in the absence of any commercial or financial relationships that could be construed as a potential conflict of interest.

Received: 03 December 2014; paper pending published: 23 December 2014; accepted: 08 January 2015; published online: 29 January 2015.

Citation: McCarthy MK and Weinberg JB (2015) The immunoproteasome and viral infection: a complex regulator of inflammation. Front. Microbiol. 6:21. doi: 10.3389/fmicb.2015.00021

This article was submitted to Virology, a section of the journal Frontiers in Microbiology. Copyright (C) 2015 McCarthy and Weinberg. This is an open-access article distributed under the terms of the Creative Commons Attribution License (CC BY). The use, distribution or reproduction in other forums is permitted, provided the original author(s) or licensor are credited and that the original publication in this journal is cited, in accordance with accepted academic practice. No use, distribution or reproduction is permitted which does not comply with these terms. 